\title{
Progress in ${ }^{13} \mathrm{C}$ and ${ }^{1} \mathrm{H}$ solid-state nuclear magnetic resonance for paramagnetic systems under very fast magic angle spinning
}

\author{
Nalinda P. Wickramasinghe, ${ }^{1}$ Medhat A. Shaibat, ${ }^{1}$ Christopher R. Jones, ${ }^{1}$ \\ Leah B. Casabianca, ${ }^{2}$ Angel C. de Dios, ${ }^{2}$ John S. Harwood, ${ }^{3}$ and Yoshitaka Ishii, ${ }^{1}$ a) \\ ${ }_{1}^{1}$ Department of Chemistry, University of Illinois at Chicago, 845 W Taylor St., Chicago, Illinois 60607, USA \\ ${ }^{2}$ Department of Chemistry, Georgetown University, 37th and O Streets NW, Washington, DC 20057, USA \\ ${ }^{3}$ Department of Chemistry, Purdue University, 560 Oval Drive, West Lafayette, Indiana 47907, USA
}

(Received 26 November 2007; accepted 17 December 2007; published online 7 February 2008)

\begin{abstract}
High-resolution solid-state NMR (SSNMR) of paramagnetic systems has been largely unexplored because of various technical difficulties due to large hyperfine shifts, which have limited the success of previous studies through depressed sensitivity/resolution and lack of suitable assignment methods. Our group recently introduced an approach using "very fast" magic angle spinning (VFMAS) for SSNMR of paramagnetic systems, which opened an avenue toward routine analyses of small paramagnetic systems by ${ }^{13} \mathrm{C}$ and ${ }^{1} \mathrm{H}$ SSNMR [Y. Ishii et al., J. Am. Chem. Soc. 125, 3438 (2003); N. P. Wickramasinghe et al., ibid. 127, 5796 (2005)]. In this review, we discuss our recent progress in establishing this approach, which offers solutions to a series of problems associated with large hyperfine shifts. First, we demonstrate that MAS at a spinning speed of $20 \mathrm{kHz}$ or higher greatly improves sensitivity and resolution in both ${ }^{1} \mathrm{H}$ and ${ }^{13} \mathrm{C}$ SSNMR for paramagnetic systems such as $\left.\mathrm{Cu}(\mathrm{II})(\mathrm{DL}-\mathrm{alanine})_{2} \cdot \mathrm{H}_{2} \mathrm{O}(\mathrm{Cu} \text { (DL-Ala })_{2}\right)$ and $\mathrm{Mn}(\mathrm{acac})_{3}$, for which the spectral dispersions due to ${ }^{1} \mathrm{H}$ hyperfine shifts reach 200 and $700 \mathrm{ppm}$, respectively. Then, we introduce polarization transfer methods from ${ }^{1} \mathrm{H}$ spins to ${ }^{13} \mathrm{C}$ spins with high-power cross polarization and dipolar insensitive nuclei enhanced by polarization transfer (INEPT) in order to attain further sensitivity enhancement and to correlate ${ }^{1} \mathrm{H}$ and ${ }^{13} \mathrm{C}$ spins in two-dimensional (2D) SSNMR for the paramagnetic systems. Comparison of ${ }^{13} \mathrm{C}$ VFMAS SSNMR spectra with ${ }^{13} \mathrm{C}$ solution NMR spectra revealed superior sensitivity in SSNMR for $\mathrm{Cu}(\mathrm{DL}-\mathrm{Ala})_{2}, \mathrm{Cu}(\mathrm{Gly})_{2}$, and $\mathrm{V}(\mathrm{acac})_{3}$. We discuss signal assignment methods using one-dimensional (1D) ${ }^{13} \mathrm{C}$ SSNMR ${ }^{13} \mathrm{C}-{ }^{1} \mathrm{H}$ rotational echo double resonance (REDOR) and dipolar INEPT methods and $2 \mathrm{D}{ }^{13} \mathrm{C} /{ }^{1} \mathrm{H}$ correlation SSNMR under VFMAS, which yield reliable assignments of ${ }^{1} \mathrm{H}$ and ${ }^{13} \mathrm{C}$ resonances for $\mathrm{Cu}(\mathrm{Ala}-\mathrm{Thr})$. Based on the excellent sensitivity/resolution and signal assignments attained in the VFMAS approach, we discuss methods of elucidating multiple distance constraints in unlabeled paramagnetic systems by combing simple measurements of ${ }^{13} \mathrm{C} T_{1}$ values and anisotropic hyperfine shifts. Comparison of experimental ${ }^{13} \mathrm{C}$ hyperfine shifts and ab initio calculated shifts for $\alpha$ - and $\beta$-forms of $\mathrm{Cu}(8 \text {-quinolinol })_{2}$ demonstrates that ${ }^{13} \mathrm{C}$ hyperfine shifts are parameters exceptionally sensitive to small structural difference between the two polymorphs. Finally, we discuss sensitivity enhancement with paramagnetic ion doping in ${ }^{13} \mathrm{C}$ SSNMR of nonparamagnetic proteins in microcrystals. Fast recycling with exceptionally short recycle delays matched to short ${ }^{1} \mathrm{H} T_{1}$ of $\sim 60 \mathrm{~ms}$ in the presence of $\mathrm{Cu}(\mathrm{II})$ doping accelerated $1 \mathrm{D}{ }^{13} \mathrm{C}$ SSNMR for ubiquitin and lysozyme by a factor of $7.3-8.4$ under fast MAS at a spinning speed of $40 \mathrm{kHz}$. It is likely that the VFMAS approach and use of paramagnetic interactions are applicable to a variety of paramagnetic systems and nonparamagnetic biomolecules. (C) 2008 American Institute of Physics. [DOI: 10.1063/1.2833574]
\end{abstract}

\section{INTRODUCTION}

More than one-third of the elements in the Periodic Table exhibit paramagnetism. In nature, paramagnetic metal ions are essential as reaction centers in metalloenzymes. ${ }^{1,2}$ Organometallics or metal coordination complexes containing paramagnetic ions play indispensable roles in modern materials science ${ }^{3}$ and synthetic chemistry ${ }^{4}$ in solid forms. A variety of paramagnetic organic complexes have been developed as bioactive compounds including anticancer and

\footnotetext{
${ }^{\text {a) }}$ Author to whom correspondence should be addressed. Electronic mail: yishii@uic.edu.
}

antitumor drugs, ${ }^{5}$ which are often administered as solid substances. Their morphologies and structures in solids substantially differentiate stability and bioavailability of these drugs. ${ }^{6,7}$ In contrast, development of novel paramagnetic complexes has been often hindered by lack of efficient characterization methods, in particular, for noncrystalline solids.

High-resolution solid-state NMR (SSNMR) using magic angle spinning (MAS) is a powerful technique for characterization and structural analysis of diamagnetic systems in solids, including noncrystalline organic materials and biomolecules. ${ }^{8-10}{ }^{13} \mathrm{C}$ and ${ }^{1} \mathrm{H}$ SSNMR have been the most widely used methods for diamagnetic organic solid 
materials. ${ }^{8,10,11}$ In contrast, for paramagnetic systems, large spectral dispersion due to hyperfine shifts traditionally imposed severe technical difficulties in high-resolution ${ }^{13} \mathrm{C}$ and ${ }^{1} \mathrm{H}$ SSNMR studies. ${ }^{12}$ Although SSNMR of ${ }^{31} \mathrm{P},{ }^{7} \mathrm{Li} /{ }^{6} \mathrm{Li}$, and other abundant spins has been shown to be effective for analysis of paramagnetic inorganic systems, ${ }^{13}$ these options are often not available for a variety of paramagnetic complexes. For paramagnetic systems, various techniques developed for diamagnetic systems have failed because of the large shift dispersion due to hyperfine shifts. For example, insufficient ${ }^{1} \mathrm{H}$ or ${ }^{1} \mathrm{H}-{ }^{1} \mathrm{H}$ rf decoupling for paramagnetic systems typically caused severe loss of resolution in ${ }^{1} \mathrm{H}$ and ${ }^{13} \mathrm{C}$ SSNMR spectra because large spectral bandwidths in paramagnetic systems are not effectively excited by limited rf fields that have been available at traditional SSNMR probes. Also, large hyperfine shifts mask the diamagnetic shifts that are characteristic of chemical groups, making signal assignment difficult without isotope labeled samples. ${ }^{14,15}$ Despite previous novel attempts on the challenging systems, ${ }^{14-18}$ it has been difficult to establish SSNMR methodologies applicable to a broad range of paramagnetic systems. Our group recently introduced a simple and effective approach for SSNMR of paramagnetic systems using fast MAS at a spinning speed of $20 \mathrm{kHz}$ or more, which we call very-fast MAS (VFMAS) approach. ${ }^{19,20}$ This approach has substantially simplified SSNMR spectroscopy of paramagnetic systems by eliminating strong anisotropic interactions such as ${ }^{1} \mathrm{H}-{ }^{13} \mathrm{C}$ and ${ }^{1} \mathrm{H}-{ }^{1} \mathrm{H}$ dipolar couplings and ${ }^{1} \mathrm{H}$ and ${ }^{13} \mathrm{C}$ pseudocontact shifts by VFMAS without rf pulses. In a framework of the VFMAS approach, our group and others have established methods for signal assignments, sensitivity enhancement, and structural elucidation for routine applications of ${ }^{13} \mathrm{C}$ and ${ }^{1} \mathrm{H}$ SSNMR analysis on unlabeled paramagnetic materials. ${ }^{19-26}$ Potential targets of the applications include a wide variety of paramagnetic systems such as drugs, ${ }^{27}$ catalysts ${ }^{22}$ coordination polymers, ${ }^{23}$ hemes, ${ }^{26,28}$ nanocomposites, ${ }^{29}$ and nanoparticles. ${ }^{30}$ These SSNMR studies on small paramagnetic systems also stimulated recent progress in SSNMR of paramagnetic biomolecules. ${ }^{31-34}$ Applications of SSNMR using paramagnetic interactions for natively nonparamagnetic biomolecules are also gaining momentum. $33,35,36$

In this review, we will provide an overview of our recent progress of the VFMAS approach on small paramagnetic systems for sensitivity enhancement, signal assignment, and structural elucidations. We will also discuss an approach for sensitivity enhancements in ${ }^{13} \mathrm{C}$ cross polarization MAS (CPMAS) of hydrated proteins in microcrystals by ${ }^{1} \mathrm{H} T_{1}$ reduction with paramagnetic ion doping and fast signal acquisition.

\section{II. ${ }^{1} \mathrm{H}$ SSNMR FOR PARAMAGNETIC SYSTEMS}

\section{A. Spinning-speed dependence and sensitivity of ${ }^{1} \mathrm{H}$ MAS NMR}

In Fig. 1, we show ${ }^{1} \mathrm{H}$ MAS SSNMR spectra of unlabeled $\mathrm{Cu}(\mathrm{II})(\mathrm{DL}-\mathrm{Ala})_{2} \cdot \mathrm{H}_{2} \mathrm{O} \quad[(\mathrm{a})-(\mathrm{c})]$ and $\mathrm{Mn}(\mathrm{III})(\mathrm{acac})_{3}$ [(d)-(f)] at different spinning speeds. At $5 \mathrm{kHz}$ MAS, in Figs. 1(c) and 1(f), no signals are identified for these systems

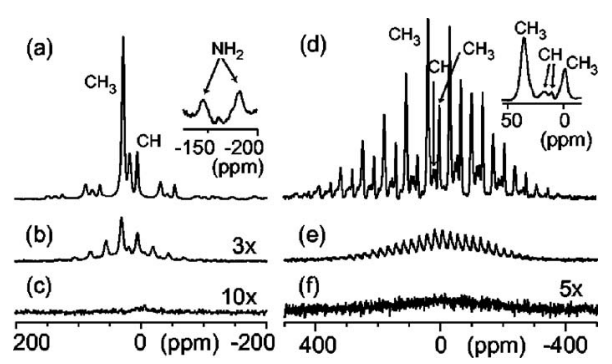

FIG. 1. ${ }^{1} \mathrm{H}$ MAS spectra of $\mathrm{Cu}(\text { DL-Ala })_{2} \cdot \mathrm{H}_{2} \mathrm{O}[(\mathrm{a})-(\mathrm{c})]$ and $\mathrm{Mn}(\mathrm{acac})_{3}$ [(d)-(f)] at spinning speeds of (a) 24, [(b) and (e)] 10, [(c) and (f)] 5, and (d) $27.8 \mathrm{kHz}$ obtained at ${ }^{1} \mathrm{H}$ frequency of $400.2 \mathrm{MHz}$ with one-pulse excitation and a rotor-synchronous echo with four scans for each spectrum. The two insets in (a) and (d) are the expanded regions of $\mathrm{NH}_{2}$ signals in (a) and centerline position in (d). The sample amount was 17 and $14 \mathrm{mg}$ for $\mathrm{Cu}(\mathrm{DL}-\mathrm{Ala})_{2}$ and $\mathrm{Mn}(\mathrm{acac})_{3}$, respectively. The assignment was based on separate $2 \mathrm{D}{ }^{13} \mathrm{C} /{ }^{1} \mathrm{H}$ correlation NMR experiments and Ref. 14. Total experimental times were only $18 \mathrm{~ms}$ [(a)-(c)] and $12 \mathrm{~ms}$ [(d)-(f)]. The spectra in (b), (c), and (f) are vertically expanded as indicated.

because of line broadening due to large ${ }^{1} \mathrm{H}-{ }^{1} \mathrm{H}$ couplings and ${ }^{1} \mathrm{H}$ anisotropic hyperfine shifts. Clearly, very limited resolution and sensitivity are obtained by the conventional MAS. In contrast, as shown in Figs. 1(a) and 1(d), VFMAS dramatically improves the sensitivity and resolution for both systems. Excellent sensitivity and resolution are displayed for $\mathrm{Cu}$ (DL-Ala) $)_{2}$ at $24 \mathrm{kHz}$ in Fig. 1(a). The results demonstrate that VFMAS efficiently removes broadening due to ${ }^{1} \mathrm{H}-{ }^{1} \mathrm{H}$ dipolar couplings and ${ }^{1} \mathrm{H}$ hyperfine shifts. ${ }^{20} \mathrm{Al}-$ though only weak signals for $\mathrm{NH}_{2}$ are observed at -144 and $-178 \mathrm{ppm}$, this is because the $\mathrm{NH}_{2}$ protons are directly coordinated to $\mathrm{Cu}(\mathrm{II})$ and subject to significant anisotropic hyperfine shifts. ${ }^{14}$ As discussed previously, the assignments can be obtained by separate two-dimensional (2D) ${ }^{13} \mathrm{C} /{ }^{1} \mathrm{H}$ chemical-shift correlation NMR under VFMAS, ${ }^{25}$ except for $\mathrm{NH}_{2}$, for which the assignment was adopted from the previous ${ }^{2} \mathrm{D}$ NMR study. ${ }^{14}$ For $\mathrm{Mn}(\mathrm{acac})_{3}$, the spectrum in Fig. 1(d) shows numerous sidebands remaining even under VFMAS at $27.8 \mathrm{kHz}$. However, the center peaks are well resolved, as shown in the inset. A large number of sidebands arise from anisotropic hyperfine shifts. The anisotropies in the hyperfine shifts are primarily attributed to pseudocontact shifts (also called dipolar shifts), which are proportional to $(S+1) S / R_{\mathrm{IS}}{ }^{3}$, where $S$ is an electron spin number, and $R_{\mathrm{IS}}$ is the distance between the nuclear spin $I$ and the electron spin $S$ at the paramagnetic metal center. ${ }^{12,17}$ Because $S$ for $\mathrm{Mn}(\mathrm{III})$ is 2 [cf. $S=\frac{1}{2}$ for $\mathrm{Cu}(\mathrm{II})$ ], it is reasonable that more sidebands were observed for $\mathrm{Mn}(\mathrm{acac})_{3}$. The linewidths in (a) and (d) are comparable to those for diamagnetic systems. The large spectral dispersion of ${ }^{1} \mathrm{H}$ chemical shifts provides excellent resolution, which allows for the characterization of paramagnetic systems by one-dimensional (1D) ${ }^{1} \mathrm{H}$ SSNMR.

\section{B. Sensitivity of ${ }^{1} \mathrm{H}$ SSNMR under VFMAS}

The surprising feature of ${ }^{1} \mathrm{H}$ SSNMR for paramagnetic systems under VFMAS is its high sensitivity. ${ }^{20}$ For example, the ${ }^{1} \mathrm{H}$ spectra in Figs. 1(a) and 1(d) were obtained for $\sim 15 \mathrm{mg}$ of the samples in total experimental times of only 18 and $12 \mathrm{~ms}$, respectively. We recently used the high sensitivity for characterizing paramagnetic systems at as low as 
$20 \mathrm{nmol}(\sim$ several $\mu \mathrm{g})$ by ${ }^{1} \mathrm{H}$ SSNMR within experimental times of 2-10 min. ${ }^{20}$ By contrast, there has been a popular conception that the sensitivity of SSNMR for paramagnetic systems is significantly lower than that for diamagnetic systems because of paramagnetic broadening. Here, we briefly outline how this conception is not necessarily true after the introduction of the VFMAS approach. Sensitivity of Fourier transform NMR with a matched window function is generally given by ${ }^{37}$

$$
\xi=\left\langle s(t)^{2}\right\rangle^{1 / 2}\left(t_{\max } / T\right)^{1 / 2} / \rho_{N},
$$

where $s(t)$ is an envelope function of a free induction decay (FID), $t_{\max }$ is an acquisition period of a FID, $T$ is a recycle time or an interval between two scans, the factor $\left\langle s^{2}\right\rangle$ is the average signal power, and $\rho_{N}$ denotes the root-mean-squared (rms) noise amplitude in a unit bandwidth. For simplicity, we assume that $s(t)$ is given by an exponential decay, as $s(t)$ $=\exp \left(-t / T_{2}\right)$. When $t_{\max }$ is matched to $T_{2}$, as $t_{\max }=c T_{2}$ for a given constant $c,\left\langle s^{2}\right\rangle$ is independent of $T_{2}$. Thus, the sensitivity, $\xi$, depends only on the receiver duty factor, $\left(t_{\max } / T\right)$. In SSNMR experiments, $T$ is usually adjusted to $k T_{1}$ $(k \sim 3)$ and, hence, $t_{\max } / T=(c / k) T_{2} / T_{1}$. In this case,

$$
\xi=[\{1-\exp (-2 c)\} / 2]^{1 / 2}\left(T_{2} / k T_{1}\right)^{1 / 2} / \rho_{N} .
$$

For ${ }^{1} \mathrm{H}$ SSNMR of diamagnetic systems, $T_{2} / T_{1}$ is only about $0.03 \%-0.1 \%\left(T_{2} \sim 0.3 \mathrm{~ms}\right.$ and $\left.T_{1} \sim 0.3-1 \mathrm{~s}\right)$. On the other hand, for small paramagnetic systems under VFMAS, $T_{2} / T_{1}$ is as large as $5 \%-30 \%\left(T_{2} \sim 0.1-0.3 \mathrm{~ms}\right.$ and $\left.T_{1} \sim 1-2 \mathrm{~ms}\right)$ because of enhanced resolution by VFMAS and short ${ }^{1} \mathrm{H} T_{1}$ values. Hence, when sidebands are sufficiently suppressed by VFMAS and reasonable resolution is obtained, the theoretical sensitivity of ${ }^{1} \mathrm{H}$ SSNMR for paramagnetic systems can be 10-30-fold greater than that for diamagnetic systems with our VFMAS approach. ${ }^{20}$ As will be discussed below, the sensitivity enhancement by fast recycling under VFMAS is also highly effective for ${ }^{13} \mathrm{C}$ SSNMR of paramagnetic systems.

\section{III. ${ }^{13} \mathrm{C}$ SSNMR OF PARAMAGNETIC SYSTEMS UNDER VFMAS}

\section{A. Spinning-speed dependence of ${ }^{13} \mathrm{C}$ MAS spectra}

Figures 2(a)-2(c) show the spinning-speed $\left(\omega_{R} / 2 \pi\right)$ dependence of ${ }^{13} \mathrm{C}$ MAS SSNMR spectra of unlabeled $\mathrm{Cu}$ (DL-Ala) ${ }_{2}$ obtained with high-power continuous wave (cw) ${ }^{1} \mathrm{H}$ rf decoupling $(100 \mathrm{kHz})$. In Fig. 2(a), at $\omega_{R} / 2 \pi$ $=5 \mathrm{kHz}$, only one signal assigned to the $\mathrm{CH}_{3}$ group is visible around $200 \mathrm{ppm}$, reflecting the fact that this ${ }^{13} \mathrm{CH}_{3}$ has a relatively small anisotropic hyperfine shift. Signals for ${ }^{13} \mathrm{CO}_{2}^{-}$and ${ }^{13} \mathrm{CH}$ are within the noise level because of the signal splitting into many sidebands and the line broadening. On the other hand, Fig. 2(c) obtained at $\omega_{R} / 2 \pi=24 \mathrm{kHz}$ clearly displays three peaks for the $\mathrm{CH}_{3}(172 \mathrm{ppm}), \mathrm{CO}$ $(-191 \mathrm{ppm})$, and $\mathrm{CH}(-276 \mathrm{ppm})$ groups in $\mathrm{Cu}(\mathrm{DL}-\mathrm{Ala})_{2}$ with improved resolution and sensitivity. Figure 2(d) shows the ${ }^{13} \mathrm{C}$ VFMAS spectrum at $\omega_{R} / 2 \pi=24 \mathrm{kHz}$ without ${ }^{1} \mathrm{H}$ rf decoupling. The resolution in (d) is superior to that in (c), in particular, for the $\mathrm{CH}$ signal. This suggests that VFMAS efficiently removes ${ }^{1} \mathrm{H}-{ }^{13} \mathrm{C}$ dipolar couplings regardless of

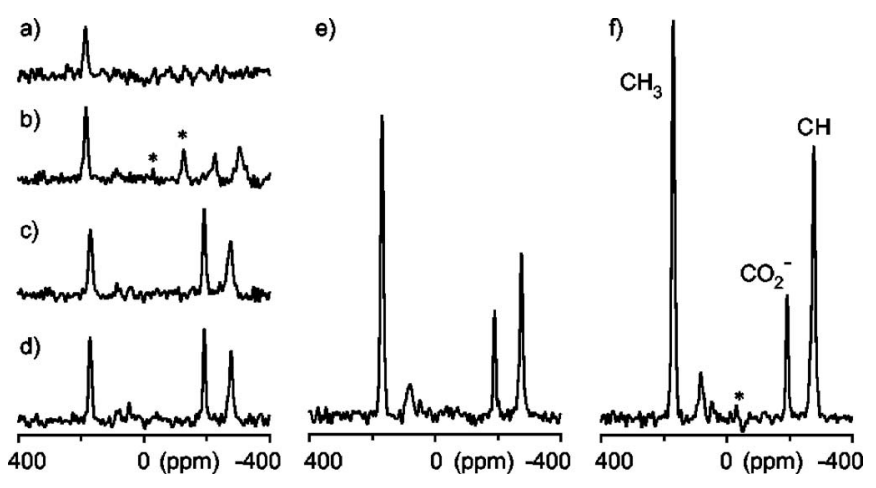

FIG. 2. ${ }^{13} \mathrm{C}$ MAS spectra of $\mathrm{Cu}(\mathrm{DL}-\mathrm{Ala})_{2} \cdot\left(\mathrm{H}_{2} \mathrm{O}\right)$ obtained at ${ }^{13} \mathrm{C} \mathrm{NMR}$ frequency of $100.6 \mathrm{MHz}$ with $[(\mathrm{a})-(\mathrm{d})]$ a single $\pi / 2$-pulse excitation, (e) adiabatic CP, and (f) dipolar INEPT. The spectra in (a)-(c) were acquired at spinning speeds of (a) 5, (b) 10 , and (c) $24 \mathrm{kHz}$ under high-power ${ }^{1} \mathrm{H} \mathrm{cw}$ rf decoupling $(100 \mathrm{kHz})$ with a recycle delay of $0.1 \mathrm{~s}$. The spectra in (d), (e), and (f) were acquired without ${ }^{1} \mathrm{H}$ rf decoupling and with a recycle delay of 100, 50, and $3.5 \mathrm{~ms}$, respectively. For each spectrum, a total experimental time was 1 min with [(a)-(d)] 614, (e) 1200, or (f) 13556 scans. A rotorsynchronous echo $\left(\tau_{R^{-}} \pi-\tau_{R}\right)$ was used prior to a signal acquisition. In (f), the dipolar INEPT pulse sequence (Ref. 25) was used with $\tau=27 \mu \mathrm{s}$. The spectra in (e) and (f) are scaled so that all the spectra display a common noise level in the figure. The recycle delays for (a)-(d) and (f) were matched to three times of ${ }^{13} \mathrm{C}$ and ${ }^{1} \mathrm{H} T_{1}$, respectively. The recycle time in (e) was restricted by a rf duty factor $(1 \%)$ to prevent a probe arcing. The ${ }^{13} \mathrm{C}$ pulse widths for $\pi / 2$ and $\pi$-pulses were 2.5 and $5.0 \mu \mathrm{s}$, respectively. In the CP experiment, the ${ }^{13} \mathrm{C}$ rf field was swept from 107.5 to $124.5 \mathrm{kHz}$ during a contact time of $0.5 \mathrm{~ms}$, while the ${ }^{1} \mathrm{H}$ RF field was kept constant at $92 \mathrm{kHz}$. The spinning sidebands are indicated by ${ }^{*}$ in the spectra. The sample amount was $15 \mathrm{mg}$.

large ${ }^{1} \mathrm{H}$ resonance offsets and anisotropic shifts for paramagnetic interactions, while ${ }^{1} \mathrm{H}$ rf decoupling is more sensitive to these interactions. For systems with larger anisotropic shifts or spectral dispersions in ${ }^{1} \mathrm{H}$ shifts, the effects are more significant. Figures 3(a) and 3(b) show ${ }^{13} \mathrm{C}$ MAS spectra of $\mathrm{Mn}(\mathrm{acac})_{3}$ at (a) $\omega_{R} / 2 \pi=10 \mathrm{kHz}$ and (b) $26.3 \mathrm{kHz}$ under high-power ${ }^{1} \mathrm{H} \mathrm{cw}$ rf decoupling $(100 \mathrm{kHz})$. Both spectra show limited resolution. In contrast, the ${ }^{13} \mathrm{C}$ VFMAS spectrum of $\mathrm{Mn}(\mathrm{acac})_{3}$ obtained at $26.3 \mathrm{kHz}$ without ${ }^{1} \mathrm{H}$ rf decoupling [Fig. 3(c)] shows notable resolution enhancement. This clearly demonstrates the effectiveness of our VFMAS approach for paramagnetic systems having extremely large hyperfine shifts.

\section{B. Sensitivity enhancement by polarization transfer}

Cross polarization ${ }^{38}(\mathrm{CP})$ has been one of the indispensable techniques in ${ }^{13} \mathrm{C}$ SSNMR. However, large shift dispersion due to hyperfine shifts has made this technique ineffective for many paramagnetic systems. In a few successful cases, including the initial high-resolution ${ }^{13} \mathrm{C}$ SSNMR for paramagnetic systems by Chack et al. ${ }^{39}$ signals within a limited bandwidth $(\sim 200 \mathrm{ppm})$ were observed at a lower field $\left({ }^{1} \mathrm{H}\right.$ frequency $\left.\sim 200 \mathrm{MHz}\right){ }^{39,40}$ For systems having larger shift dispersion, CP transfer efficiency is suppressed because large resonance offsets cause deviations from the HartmannHahn condition with the limited rf intensities that are available in conventional MAS probes. We recently demonstrated that further sensitivity enhancement in ${ }^{13} \mathrm{C}$ SSNMR spectra for paramagnetic systems can be obtained using polarization transfer from ${ }^{1} \mathrm{H}$ spins with the strong rf fields available in 
(a)

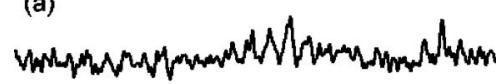

(b)

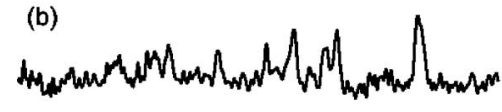

(c)

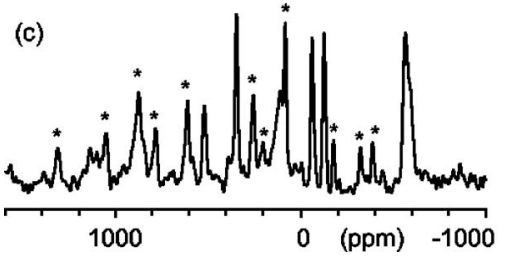

(d)

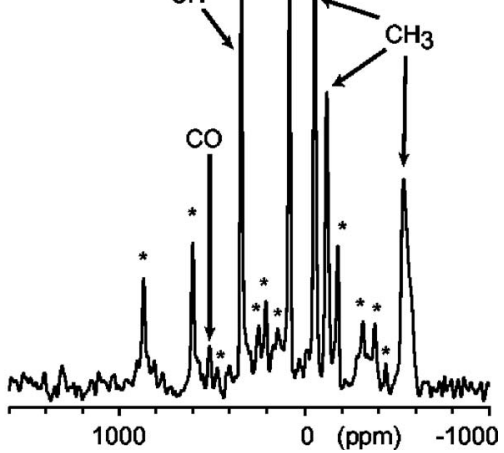

FIG. 3. ${ }^{13} \mathrm{C}$ MAS spectra of Mn(acac) 3 obtained at ${ }^{13} \mathrm{C}$ NMR frequency of $100.6 \mathrm{MHz}$ with $[(\mathrm{a})-(\mathrm{c})]$ a single $\pi / 2-$ pulse excitation and (d) dipolar INEPT. The spectra in (a) and (b) were acquired at spinning speeds of (a) 10 and (b) $26.3 \mathrm{kHz}$ under high-power ${ }^{1} \mathrm{H}$ cw rf decoupling (100 kHz) with a recycle delay of $45 \mathrm{~ms}$. The spectra in (c) and (d) were acquired at $26.3 \mathrm{kHz}$ without ${ }^{1} \mathrm{H}$ rf decoupling and with recycle delays of 15 and $1.5 \mathrm{~ms}$, respectively. For each spectrum, a total experimental time was 10 min with [(a) and (b)] 13110 , (c) 39 940, or (d) 364540 scans. A rotor-synchronous echo ( $\tau_{R^{-}} \pi$ - $\left.\tau_{R}\right)$ was used prior to a signal acquisition. In (d), the dipolar INEPT pulse sequence (Ref. 25) was used with $\tau=9 \mu$ s. The spinning speed for (c) and (d) was $26.3 \mathrm{kHz}$. The spectra in (c) and (d) are scaled so that all the spectra display a common noise level in the figure. The recycle delays for (c) and (d) were matched to three times of ${ }^{13} \mathrm{C}$ and ${ }^{1} \mathrm{H} T_{1}$, respectively. The recycle times in (a) and (b) were restricted by a rf duty factor (1\%) to prevent a probe arcing. The ${ }^{13} \mathrm{C}$ and ${ }^{1} \mathrm{H} \pi / 2$-pulse widths were $1.7 \mu$ s. The spinning sidebands are indicated by ${ }^{*}$ in the spectra. The sample amount was 14 mg.

VFMAS probes. ${ }^{19}$ Figure 2(e) shows the ${ }^{13} \mathrm{C}$ CP-VFMAS spectrum of $\mathrm{Cu}(\mathrm{DL}-\mathrm{Ala})_{2}$ obtained with high-power ramped CP. Because of short ${ }^{1} \mathrm{H} T_{1}$ values, it is possible to acquire a greater number of scans within a given experimental time. Clearly, the sensitivity was significantly enhanced in Fig. 2(e), compared with (d). The sensitivity enhancement factors in Fig. 2(e) are 2.2-3.6 and 1.2, compared with the spectrum in Fig. 2(d) for protonated and nonprotonated ${ }^{13} \mathrm{C}$ signals, respectively. More recently, our group and others introduced dipolar insensitive nuclei enhanced by polarization transfer (INEPT) sequence ${ }^{41}$ for paramagnetic systems, which permits us to further reduce recycle times by polarization transfer using only short rf pulses. ${ }^{22,25}$ As a result, as shown in Fig. 2(f), further sensitivity enhancement is possible. Compared with the spectrum in Fig. 2(b) under moderate MAS at $10 \mathrm{kHz}$, which was utilized in previous ${ }^{13} \mathrm{C}$ SSNMR studies for paramagnetic systems, ${ }^{14}$ the enhancement factors are $6.0,4.4$, and 8.2 for ${ }^{13} \mathrm{CH}_{3},{ }^{13} \mathrm{CO}_{2}{ }^{-}$, and ${ }^{13} \mathrm{CH}_{3}$, respectively. Thus, the excellent sensitivity and resolution in Fig. 2(f) were obtained in only $1 \mathrm{~min}$, despite the relatively small sample amount $(\sim 15 \mathrm{mg})$, which can be accommodated in the VFMAS probe. The sensitivity in Fig. 2(f) is superior or comparable to that of the ${ }^{13} \mathrm{C}$ CPMAS spectrum of equimolar amount of L-Ala $(11.2 \mathrm{mg}) .{ }^{25}$ We will discuss signal assignment of the spectrum in a later section.

We also demonstrated the possibility of sensitivity enhancement by polarization transfer under VFMAS for samples possessing extremely large hyperfine shifts such as $\mathrm{Mn}(\mathrm{acac})_{3} \cdot{ }^{25}$ Figure $3(\mathrm{~d})$ shows a $1 \mathrm{D}{ }^{13} \mathrm{C}$ VFMAS spectrum of $\mathrm{Mn}(\mathrm{acac})_{3}$ obtained by a rapid repetition of the dipolar INEPT sequence $(1.5 \mathrm{~ms} / \mathrm{scan})$ in a common experimental time with (a)-(c) (10 min). The spectrum was obtained by setting $\tau=9 \mu \mathrm{s}\left(0.237 \tau_{R}\right)$, which provides favorable polarization transfer for both ${ }^{13} \mathrm{CH}$ and ${ }^{13} \mathrm{CH}_{3}$ groups by dipolar INEPT (see Ref. 25 about the pulse sequence and the definition of $\tau$ ), where $\tau_{R}$ denotes a rotor cycle. The resulting spectrum displays strong signals only for protonated ${ }^{13} \mathrm{C}$ because of the short effective transfer period. Clearly, a relatively complicated spectrum in Fig. 3(c) is simplified in (d) because of the semiselective enhancement for protonated ${ }^{13} \mathrm{C}$ signals. The signal assignment in Fig. 3(d) was obtained by a separate ${ }^{13} \mathrm{C}-{ }^{1} \mathrm{H}$ rotational echo double resonance (REDOR) experiment. ${ }^{19}$ The sensitivity enhancement factors in this approach for protonated ${ }^{13} \mathrm{C}$ are up to 2.8 and 20 , compared with the spectra in (c) $\left(\omega_{R} / 2 \pi=26.3 \mathrm{kHz}\right)$ and in (a) $\left(\omega_{R} / 2 \pi=10 \mathrm{kHz}\right)$, respectively.

\section{Comparison of ${ }^{13} \mathrm{C}$ VFMAS spectra with ${ }^{13} \mathrm{C}$ solution NMR spectra}

It has long been a problem for synthetic chemists and materials scientists that solution NMR analysis of paramagnetic systems is often subject to severe paramagnetic broadening because of long electron spin relaxation times in isolated paramagnetic molecules in solution. ${ }^{42}$ Particularly, ${ }^{13} \mathrm{C}$ NMR is often problematic because of its low sensitivity. Since excellent sensitivity was demonstrated above for paramagnetic systems, we compared the sensitivity of ${ }^{13} \mathrm{C}$ SSNMR with that of ${ }^{13} \mathrm{C}$ solution NMR in order to test the possibility of utilizing ${ }^{13} \mathrm{C}$ SSNMR as a practical analytical tool.

Figure 4 shows ${ }^{13} \mathrm{C}$ NMR spectra of $[(\mathrm{a})$ and (d)] $\mathrm{Cu}(\text { DL-Ala })_{2},[(\mathrm{~b})$ and (e) $] \mathrm{Cu}(\text { glycine })_{2}$, and $[(\mathrm{c})$ and (f) $]$ $\mathrm{V}(\mathrm{acac})_{3}$ in solids under VFMAS $[(\mathrm{a})-(\mathrm{d})]$ and in solution [(d)-(f)]. For comparison and simplicity, both solid and solution NMR spectra were obtained with single pulse excitation in a common field strength $(9.4 \mathrm{~T})$ and with comparable experimental conditions. Although longer experimental times [(d) $3 \mathrm{~h}$ and (e) $1 \mathrm{~h}$ ] were used to compensate for the smaller sample amount in the saturated solutions used for (d) and (e), no signals were identified for either case; we also confirmed that no signals were visible with recycle delays of $0.1,1$, and $3 \mathrm{~s}$ in an experimental time of $30 \mathrm{~min}$. The low sensitivity for these solution samples of $\mathrm{Cu}(\mathrm{DL}-\mathrm{Ala})_{2}$ and $\mathrm{Cu}(\mathrm{Gly})_{2}$ may be attributed to electron spin relaxation, which is much slower in solution, and to extreme paramagnetic broadening induced by the slow relaxation. ${ }^{14}$

By contrast, SSNMR spectra in Figs. 4(a) and 4(b) 


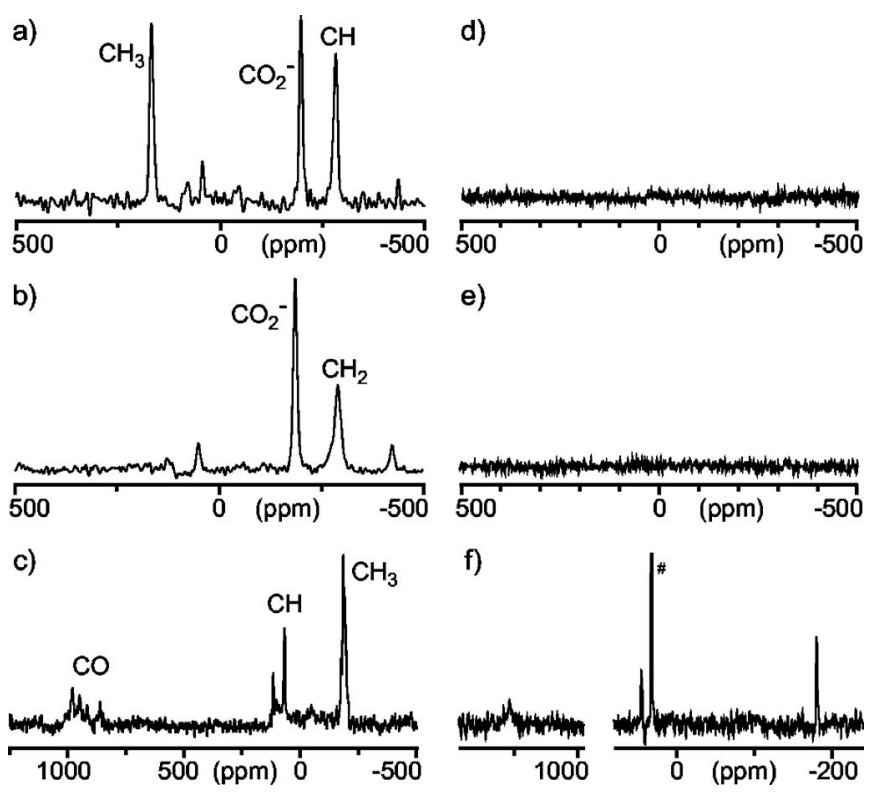

FIG. 4. Comparison of (a)-(c) ${ }^{13} \mathrm{C}$ solid-state NMR (SSNMR) and (d)-(f) ${ }^{13} \mathrm{C}$ solution NMR for [(a) and (d) $] \mathrm{Cu}(\mathrm{DL}-\mathrm{Ala})_{2}$, [(b) and (e)] $\mathrm{Cu}(\mathrm{Gly})_{2}$, and $[(\mathrm{c})$ and (f) $] \mathrm{V}(\mathrm{acac})_{3}$. SSNMR spectra were obtained with single pulse excitation under VFMAS at (a) 24.0, (b) 23.8 , and (c) $27.5 \mathrm{kHz}$. The sample amount was (a) 15, (b) 22, and (c) $13.5 \mathrm{mg}$. The total experimental time was (a) $1.7 \mathrm{~min}$ (1024 scans), (b) $8.5 \mathrm{~min}$ (5120 scans), and (c) $8.5 \mathrm{~min}$ (5120 scans). Solution NMR spectra were obtained by single $\pi / 2$-pulse excitation with ${ }^{1} \mathrm{H}$ wideband alternating-phase low-power technique for zero-residualsplitting (WALTZ-64) decoupling, as described in Sec. VII. The sample of (d) 3.8 , (e) 2.6 , and (f) $13 \mathrm{mg}$ was dissolved into $0.7 \mathrm{ml}$ of [(d) and (e) $] \mathrm{D}_{2} \mathrm{O}$ or (f) deuterated dimethyl sulfoxide (DMSO) in a standard $5 \mathrm{~mm}$ NMR tube. The saturated solutions were used for (d) and (e). The experimental times were (d) $3 \mathrm{~h}$ (102 400 scans), (e) $1 \mathrm{~h}$ (34000 scans), and (f) $8 \mathrm{~min}$ (4096 scans). The total experimental time for solution-state NMR was adjusted so the sensitivity can be compared with that of SSNMR based on signal intensity. The signals indicated by \# in (f) are solvent signals. For (d) and (e), we confirmed that no signals were visible with recycle delays of 0.1 , 1 , and $3 \mathrm{~s}$ within an experimental time of $30 \mathrm{~min}$.

clearly show excellent sensitivity and resolution after only (a) 2 and (b) 9 min of signal acquisition. Even in the case of a highly soluble complex, $\mathrm{V}(\mathrm{acac})_{3}$, the sensitivity in ${ }^{13} \mathrm{C}$ SSNMR in (c) is still superior to that in the corresponding solution NMR spectrum in (f) even without polarization transfer. The ${ }^{13} \mathrm{C}$ solution NMR of $\mathrm{V}(\mathrm{acac})_{3}$ in (f) exhibited peak positions $(1110,40$, and $-180 \mathrm{ppm})$ similar to those in SSNMR in (c). This result suggests that the electronic structure of $\mathrm{V}(\mathrm{acac})_{3}$ may be similar in solution and in the solid. It is noteworthy that multiple signals assigned to the same chemical groups in (c) suggest the reduced symmetry in solids, ${ }^{19}$ which is consistent with a recent high-resolution $\mathrm{x}$-ray crystallography study. ${ }^{43}$ The signal assignments in the SSNMR spectra in Figs. 4(a)-4(c) were made based on our recent work, ${ }^{13} \mathrm{C}-{ }^{1} \mathrm{H}$ REDOR ${ }^{19}$ and/or the dipolar INEPT method. ${ }^{25}$ These results suggest that ${ }^{13} \mathrm{C}$ VFMAS SSNMR offers effective means for analyzing relatively small paramagnetic complexes for which ${ }^{13} \mathrm{C}$ solution NMR spectra are difficult to observe or analyze.

\section{Assignment and connectivity by recoupling and $2 \mathrm{D}{ }^{13} \mathrm{C} /{ }^{1} \mathrm{H}$ and ${ }^{13} \mathrm{C} /{ }^{13} \mathrm{C}$ correlation methods}

$2 \mathrm{D}{ }^{13} \mathrm{C} /{ }^{1} \mathrm{H}$ correlation NMR has been widely used for spectral assignments and structural analysis of interesting materials such as polymers and biomolecules. ${ }^{10,37}$ This method is particularly useful when SSNMR characterization is carried out for unlabeled samples, although applicability of this method to paramagnetic systems was not established because of difficulties in polarization transfer and ${ }^{1} \mathrm{H}$ and ${ }^{1} \mathrm{H}-{ }^{1} \mathrm{H}$ rf decoupling until our recent introduction of the VFMAS approach. ${ }^{19}$ With the broadband polarization transfer methods and ${ }^{1} \mathrm{H}-{ }^{1} \mathrm{H}$ decoupling by VFMAS, ${ }^{20}$ we can routinely apply $2 \mathrm{D}{ }^{13} \mathrm{C} /{ }^{1} \mathrm{H}$ correlation SSNMR for paramagnetic systems, which provides assignments and connectivity of chemical groups. ${ }^{19}$

Figure 5 shows the $2 \mathrm{D}{ }^{13} \mathrm{C} /{ }^{1} \mathrm{H}$ chemical-shift correlation spectra of $\mathrm{Cu}(\mathrm{Ala}-\mathrm{Thr})$ obtained with (c) dipolar INEPT transfer and (d) adiabatic $\mathrm{CP}$ transfer, together with $1 \mathrm{D}{ }^{13} \mathrm{C}$ spectra obtained using (a) ${ }^{13} \mathrm{C}-{ }^{1} \mathrm{H}$ REDOR (Ref. 19) and (b) dipolar INEPT (Ref. 25) pulse sequences. The spectrum in Fig. 5(c) was acquired with the dipolar INEPT transfer using a short $\tau$ of $4.0 \mu \mathrm{s}\left(\omega_{R} / 2 \pi=25.0 \mathrm{kHz}\right)$, which limits the effective polarization transfer time to a relatively short period; thus, strong signals should be assigned to protonated ${ }^{13} \mathrm{C} .{ }^{26}$ The excellent resolution in (c) was obtained after $6 \mathrm{~h}$ of signal acquisition for this moderately complex unlabeled sample. The signal assignments indicated in Fig. 5(a) were performed on the basis of comparison of the signal intensities of the 1D dipolar INEPT spectra obtained with $\tau=4$ and $\tau=13 \mu$ s (b) and ${ }^{13} \mathrm{C}-{ }^{1} \mathrm{H}$ REDOR experiments (a). ${ }^{19,25}$ Our group and others have previously shown that $1 \mathrm{D}{ }^{13} \mathrm{C}-{ }^{1} \mathrm{H}$ REDOR (Ref. 19) and 1D dipolar INEPT (Refs. 22 and 25) methods can be used in combination with numerical simulations to identify chemical groups for paramagnetic systems. For example, in (a), it is clear that ${ }^{13} \mathrm{CH},{ }^{13} \mathrm{CH}_{3}$, and nonprotonated ${ }^{13} \mathrm{C}$ signal intensities are distinctively dephased by the ${ }^{13} \mathrm{C}-{ }^{1} \mathrm{H}$ REDOR sequence to $\sim 13 \%, \sim 60 \%$, and $\sim 90 \%$, respectively. ${ }^{26}$ This is consistent with our numerical simulations and experiments for model compounds. ${ }^{19,25} \mathrm{In}$ the dipolar INEPT experiment in (b), nonprotonated ${ }^{13} \mathrm{C}$ show only minimum signals at $\tau=4 \mu$ s while $\mathrm{CH}$ and $\mathrm{CH}_{3}$ signals are observed. As predicted by simulations, when $\tau$ was increased to $18 \mu \mathrm{s}$, the $\mathrm{CH}$ signal decreased slightly and $\mathrm{CH}_{3}$ signal increased considerably. ${ }^{25}$ Thus, these methods allow us to distinguish different chemical groups for assignments. If needed, these methods can be combined in $2 \mathrm{D}$ ${ }^{13} \mathrm{C} /{ }^{1} \mathrm{H}$ correlation experiments, offering excellent means of signal assignments for relatively complicated paramagnetic systems.

Next, we examined the connectivities of the chemical groups for signal assignments. The spectrum in Fig. 5(d) was obtained with high-power adiabatic CP transfer of a contact time of $0.3 \mathrm{~ms}$. Interestingly, long-range cross peaks between ${ }^{13} \mathrm{C}$ and ${ }^{1} \mathrm{H}$ separated by more than one bond are visible (green circles). Tracing the long-range cross peaks allows us to identify the connectivity of chemical groups for the unlabeled metal-peptide complex, as indicated by a blue solid line (Thr) and a red dotted line (Ala). Except for ${ }^{13} \mathrm{CO}_{2}{ }^{-}$in $\mathrm{Thr}$, all the chemical groups including the $\mathrm{OH}$ group in $\mathrm{Thr}$ are correlated through the long-range cross peaks between ${ }^{1} \mathrm{H}$ and ${ }^{13} \mathrm{C}$ separated by two bonds. ${ }^{26}$ Because many organic compounds including peptides often consist of the same set 
(a)
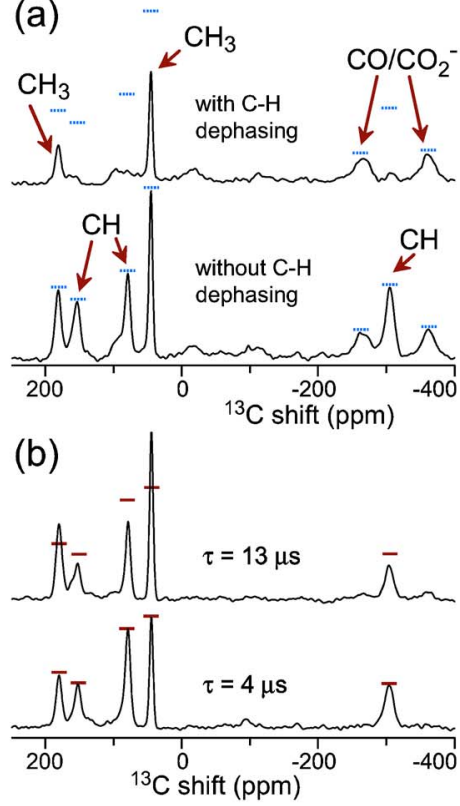

(c)

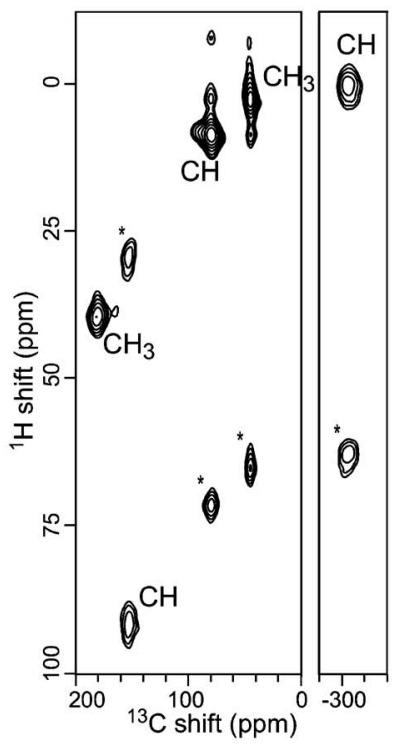

(d)

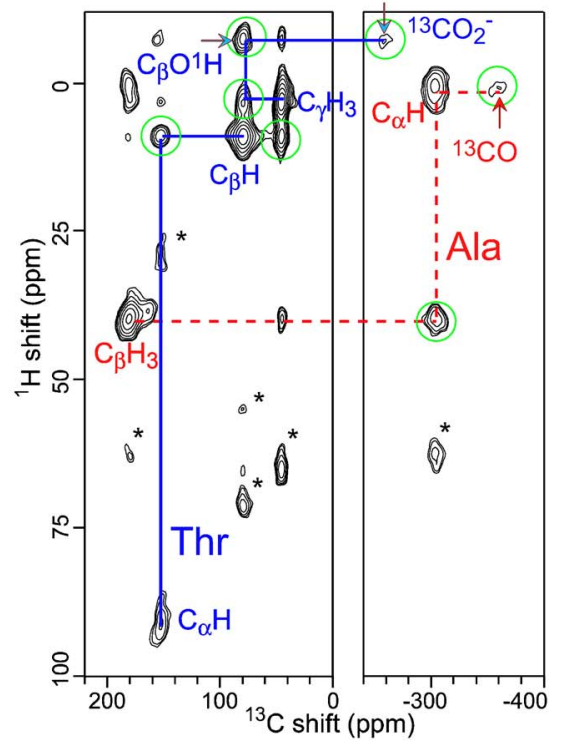

FIG. 5. (Color online) [(a) and (b)] 1D ${ }^{13} \mathrm{C}$ MAS spectra obtained using (a) ${ }^{13} \mathrm{C}-{ }^{1} \mathrm{H}$ REDOR experiment (Ref. 19), and (b) dipolar INEPT transfer (Ref. 25) for $16 \mathrm{mg}$ of $\mathrm{Cu}$ (Ala-Thr) $\cdot \frac{1}{2} \mathrm{H}_{2} \mathrm{O}$. [(c) and (d)] $2 \mathrm{D}{ }^{13} \mathrm{C} /{ }^{1} \mathrm{H}$ correlation NMR spectrum obtained with (c) dipolar INEPT transfer with $\tau=4 \mu$ s, and (d) adiabatic $\mathrm{CP}$ transfer for the same sample. All the data were collected at $-10{ }^{\circ} \mathrm{C}$ without ${ }^{1} \mathrm{H} \mathrm{rf}$ decoupling at a spinning speed of $25 \mathrm{kHz}$. The total experimental times were (a) $1.2 \mathrm{~h}$, (b) $5.6 \mathrm{~min}$, (c) $6.1 \mathrm{~h}$, and (d) $35 \mathrm{~h}$. The widths of ${ }^{1} \mathrm{H} \pi / 2$-pulse and ${ }^{13} \mathrm{C} \pi$-pulse were 1.75 and $3.50 \mu$, respectively. In (c), a total of $50 t_{1}$ complex points were recorded with a $t_{1}$ increment of $20 \mu \mathrm{s}$, recycle delays of $3 \mathrm{~ms}$, and 32768 scans for the real/imaginary component of each $t_{1}$ point. In (d), ${ }^{13} \mathrm{C}$ rf field amplitude was linearly swept from 72 to $78 \mathrm{kHz}$ with an adiabatic amplitude sweep during a contact time of $0.3 \mathrm{~ms}$, while ${ }^{1} \mathrm{H}$ rf field was kept at $100 \mathrm{kHz}$. A total of $100 t_{1}$ complex points were recorded with a $t_{1}$ increment of $10 \mu \mathrm{s}$, recycle delays of $50 \mathrm{~ms}$, and 11776 scans for the real/imaginary component of each $t_{1}$ point. The spinning sidebands are denoted by ${ }^{*}$. The signal assignments in (c) were obtained from the experiments in (a) and (b). In (d), the connectivity-based assignments were presented by color-coded lines for Ala (red dotted line) and Thr (blue solid line). In (d), green circles denote cross peaks between ${ }^{13} \mathrm{C}-{ }^{1} \mathrm{H}$ pairs that are not directly bonded.

of chemical groups, this assignment approach based on longrange couplings provides a useful means for identifying the connectivity of chemical groups in $2 \mathrm{D}{ }^{13} \mathrm{C} /{ }^{1} \mathrm{H}$ correlation SSNMR for unlabeled paramagnetic systems. As will be discussed below, the obtained assignments can be used as a basis for structural measurements with ${ }^{13} \mathrm{C} T_{1}$ and ${ }^{13} \mathrm{C}$ anisotropic hyperfine shifts.

The resolution obtained here is encouraging, suggesting that signals for larger peptides/proteins selectively ${ }^{13} \mathrm{C}$ labeled at several sites around the metal center are likely to be well resolved in 2D ${ }^{13} \mathrm{C} /{ }^{1} \mathrm{H}$ chemical-shift correlation SSNMR with VFMAS. With the natural abundance of ${ }^{13} \mathrm{C}$ at only $1 \%$ yielding the excellent sensitivity in Fig. 5 for the $\mathrm{Cu}$-dipeptide complex, we can expect sufficient sensitivity in $2 \mathrm{D}{ }^{13} \mathrm{C} /{ }^{1} \mathrm{H}$ correlation SSNMR for ${ }^{13} \mathrm{C}$-labeled peptidemetal complexes as large as 100 residues after $10 \mathrm{~h}$ of signal accumulation, assuming similar spin parameters. For applications to such ${ }^{13} \mathrm{C}$-labeled samples, we also performed a preliminary 2D ${ }^{13} \mathrm{C} /{ }^{13} \mathrm{C}$ chemical-shift correlation SSNMR experiment for uniformly ${ }^{13} \mathrm{C}$ - and ${ }^{15} \mathrm{~N}$-labeled $\mathrm{Cu}(\mathrm{DL}-\mathrm{Ala})_{2}$, as shown in Fig. 6. For $10 \mathrm{mg}$ of the sample, a nicely resolved $2 \mathrm{D}{ }^{13} \mathrm{C} /{ }^{13} \mathrm{C}$ correlation spectrum in Fig. 6 was obtained in only $3 \mathrm{~s}$ by the usage of short recycle delays of $3 \mathrm{~ms}$. Clearly, the connectivity of the carbon backbones is identified in Fig. 6. Based on the obtained sensitivity, similar sensitivity is expected for a 100 -residue ${ }^{13} \mathrm{C}$-labeled protein- $\mathrm{Cu}$ complex sample of $10 \mathrm{mg}$ within $8.3 \mathrm{~h}$.

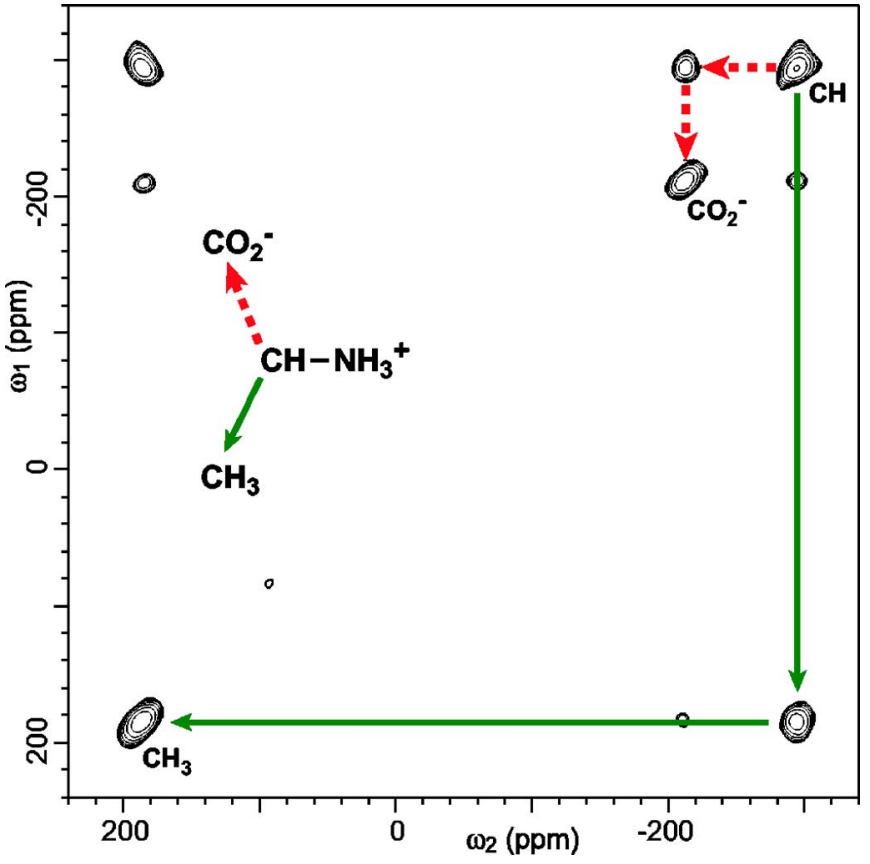

FIG. 6. (Color online) A $2 \mathrm{D}{ }^{13} \mathrm{C} /{ }^{13} \mathrm{C}$ chemical-shift correlation NMR spectrum of uniformly ${ }^{13} \mathrm{C}$ - and ${ }^{15} \mathrm{~N}$-labeled $\mathrm{Cu}(\mathrm{DL}-\mathrm{Ala})_{2}(10 \mathrm{mg})$. The spectrum was acquired at a spinning speed of $40 \mathrm{kHz}$ with ${ }^{1} \mathrm{H}-{ }^{13} \mathrm{C}$ polarization transfer by dipolar INEPT method at $-5{ }^{\circ} \mathrm{C} .{ }^{13} \mathrm{C}-{ }^{13} \mathrm{C}$ dipolar mixing was performed by the radio-frequency-driven dipolar recoupling (RFDR) sequence with a train of $4 \mu \mathrm{s}{ }^{13} \mathrm{C} \pi$ pulses rotor synchronously applied with one pulse in every rotor cycle during a mixing period of $1.6 \mathrm{~ms}$ without ${ }^{1} \mathrm{H}$ decoupling. With short recycle delays of $3 \mathrm{~ms}$, the spectrum was collected in a total experimental time of only $3 \mathrm{~s} .{ }^{13} \mathrm{C}-{ }^{13} \mathrm{C}$ polarization transfer during the RFDR mixing was found to be more efficient without ${ }^{1} \mathrm{H}$ decoupling in the fast MAS condition, compared with the data obtained under 200 or $100 \mathrm{kHz}{ }^{1} \mathrm{H}$ rf decoupling. 


\section{STRUCTURAL INFORMATION FROM PARAMAGNETIC SYSTEMS}

We recently demonstrated that the VFMAS approach allows for elucidation of structural information on paramagnetic systems. ${ }^{25,26}$ Both the relaxation times and the anisotropic hyperfine (pseudocontact) shifts contain information on the distance between ${ }^{13} \mathrm{C}$ spins and paramagnetic metal ions. We demonstrate that by combining measurements of ${ }^{13} \mathrm{C} T_{1}$ values and ${ }^{13} \mathrm{C}$ anisotropic hyperfine shifts, multiple distance constraints in a paramagnetic system can be elucidated for an unlabeled sample, for which structural characterization by SSNMR is generally difficult even for diamagnetic systems. In addition, we show that hyperfine shifts are exceptionally sensitive probes of molecular structures for paramagnetic systems. Using this property, we demonstrate applications of the VFMAS approach for distinctions of polymorphs or different supramolecular structures for paramagnetic systems.

\section{A. Metal- ${ }^{13} \mathrm{C}$ distance from ${ }^{13} \mathrm{C} T_{1}$ values}

Longitudinal relaxation times of SSNMR signals due to paramagnetic relaxation $\left(T_{1 p}\right)$ are known to be inversely proportional to $R^{6}$, where $R$ is the distance between nucleus of our interest $I$ (e.g., ${ }^{13} \mathrm{C}$ ) and a metal center $M$ if we assume that electron spin $S$ is localized at the metal center. ${ }^{2}$ In the analysis of ${ }^{1} \mathrm{H} T_{1}$ values, ${ }^{1} \mathrm{H}-{ }^{1} \mathrm{H}$ spin diffusion typically complicates the analysis; hence, in this study we limit our focus to dilute nuclei such as ${ }^{13} \mathrm{C}$ and ${ }^{15} \mathrm{~N}$. Although the $R$ dependence of $T_{1 p}$ has been a well established relationship, ${ }^{12}$ because of difficulties in assignments, only a few applications of this technique have been performed to selectively ${ }^{13} \mathrm{C}$ - and ${ }^{2} \mathrm{D}$-labeled systems. ${ }^{16}$

With the reliable signal assignment methods discussed above, we recently revisited this problem for broader applications to unlabeled paramagnetic systems. In paramagnetic solids, $T_{1 p}$ of ${ }^{13} \mathrm{C}$ and other spin- $1 / 2$ nuclei is dominated by relaxation due to dipolar spin interactions between the electron spin in the paramagnetic metal ion, $S$, and an observed nucleus, I (Solomon relaxation). ${ }^{44}$ The orientation-averaged relaxation time for the nuclear spin $I$ in rigid solids is given by $^{44,45}$

$$
\begin{aligned}
1 / T_{1 p}= & (2 / 15)\left(d_{I S}\right)^{2} S(S+1)\left\{\frac{\tau_{S}}{1+\left(\omega_{I}-\omega_{S}\right)^{2} \tau_{S}^{2}}\right. \\
& \left.+\frac{3 \tau_{S}}{1+\omega_{I}^{2} \tau_{S}^{2}}+\frac{6 \tau_{S}}{1+\left(\omega_{I}+\omega_{S}\right)^{2} \tau_{S}^{2}}\right\},
\end{aligned}
$$

with

$$
d_{I S}=\mu_{0} \hbar \gamma_{I} \gamma_{S} /\left(4 \pi R^{3}\right),
$$

where $d_{I S}$ is the dipolar coupling constant between $I$ and $S$, and $\tau_{S}$ is a correlation time of the electron spin state, $S_{Z}(t)$, $\omega_{I}$ is the NMR frequency of the spin $I, \omega_{S}$ is the electron paramagnetic resonance (EPR) frequency for the spin $S, \mu_{0}$ is the magnetic permeability, $\hbar$ is the Planck constant, and $\gamma_{K}$ is a magnetogyric ratio for spin $K(K=I$ or $S)$. This equation is valid when an isotropic $g$-tensor can be assumed for the $S$ spin. When $\left(\omega_{S} \tau_{S}\right)^{2} \gg 1$, which means that the EPR frequency
$\omega_{S}$ is, as is usually the case, greater than the EPR linewidth $\left(\sim 1 / \tau_{S}\right),{ }^{44}$ the relaxation is introduced by the dipolar term in the form of $S_{Z} I_{ \pm} \cdot{ }^{44,46}$ This interaction causes transitions only between nuclear spin states in the Solomon relaxation mechanism. Then, Eq. (3) is reduced to

$$
1 / T_{1 p}=(2 / 5)\left(d_{I S}\right)^{2} S(S+1) \frac{\tau_{S}}{1+\omega_{I}^{2} \tau_{S}^{2}} .
$$

We assume that only one paramagnetic center exists in a complex and that the paramagnetic relaxation within the complex is a dominant relaxation mechanism. Since $\tau_{S}$ can be considered as a constant for a given paramagnetic center, it is possible to determine relative distances $\left(R_{i} / R_{j}\right)$, using the relationship $\left(R_{i} / R_{j}\right)=\left(T_{1 p}{ }^{i} / T_{1 p}{ }^{j}\right)^{1 / 6}$, where $R_{k}$ denotes a distance between the paramagnetic metal and the $k$ th $I$ spin in the complex, $I_{k}$, and $T_{1 p}{ }^{k}$ is $T_{1 p}$ value for the spin $I_{k}$.

To examine the validity of this approach, we measured ${ }^{13} \mathrm{C} T_{1}$ for $\mathrm{Cu}(\mathrm{DL}-\mathrm{Ala})_{2}$ and $\mathrm{Mn}(\mathrm{acac})_{3}$ with known x-ray structures. ${ }^{47,48}$ Table I shows ${ }^{13} \mathrm{C} T_{1}$ values obtained by the inversion recovery method for $\mathrm{Cu}(\mathrm{DL}-\mathrm{Ala})_{2}$ and $\mathrm{Mn}(\mathrm{acac})_{3}$. In Table I, the relative distances estimated from the $T_{1}$ values, $\left(R / R_{\mathrm{CO}}\right)_{T 1}$, are compared with corresponding distances from x-ray structures, $\left(R / R_{\mathrm{CO}}\right)_{\mathrm{x} \text {-ray }}$, where $R_{\mathrm{CO}}$ denotes the shortest $M-{ }^{13} \mathrm{CO}_{2}{ }^{-}$and $M-{ }^{13} \mathrm{CO}$ distances for $\mathrm{Cu}(\mathrm{DL}-\mathrm{Ala})_{2}$ and $\mathrm{Mn}(\mathrm{acac})_{3}$, respectively. We also calculated ${ }^{13} \mathrm{C}-M$ distances estimated from ${ }^{13} \mathrm{C} T_{1}$ of SSNMR, $R_{T 1}$, using a set of $\left(R / R_{\mathrm{CO}}\right)_{T 1}$ and $\left(R_{\mathrm{CO}}\right)$ adopted from the $\mathrm{x}$-ray structures. Please note that only one distance was borrowed from the X-ray structures for each molecule to calculate $R_{T 1}$. For the $\mathrm{CH}_{3}$ groups, which have relatively fast relaxation rates in diamagnetic systems: $\left(1 / T_{1 \text { dia }}\right), T_{1 p}$ was obtained by $1 / T_{1 p}$ $=\left(1 / T_{1}-1 / T_{1 \mathrm{dia}}\right)$, where $T_{1 \mathrm{dia}}$ of $75 \mathrm{~ms}$ was adopted from the $T_{1}$ value obtained for L-alanine. For other chemical groups, we neglected the effect assuming that $T_{1 \text { dia }} \gg T_{1 p}$. Table I clearly shows that the relative distances estimated from the ${ }^{13} \mathrm{C} T_{1}$ values agree reasonably well with those from $\mathrm{x}$-ray distances.

Relatively small but noticeable difference between $R_{\text {x-ray }}$ and $R_{T 1}$ was observed for ${ }^{13} \mathrm{CH}_{3}$ for both $\mathrm{Cu}(\mathrm{DL}-\mathrm{Ala})_{2}(17 \%)$ and $\mathrm{Mn}(\mathrm{acac})_{3}(6 \%-11 \%)$. We consider that the difference can be attributed to intercomplex paramagnetic relaxation. When intercomplex paramagnetic couplings are included, the $T_{1}$ relaxation rate is calculated as the sum of the relaxation rates due to all the metal centers in neighboring complexes as

$$
1 / T_{1 p}{ }^{k}=\sum_{N \geqslant 0} 1 / T_{1 p}{ }^{k}{ }^{k},
$$

where $1 / T_{1 p 0}^{k}$ and $1 / T_{1 p L}^{k}(L \neq 0)$ denote relaxation rates due to intra- and intercomplex dipolar couplings, respectively, and $1 / T_{1 p N}{ }^{j}$ is given by Eq. (3) for the metal ion in the $N$ th molecule. Based on the X-ray structure of $\mathrm{Cu}(\mathrm{DL}-\mathrm{Ala})_{2}$, we estimated intracomplex contributions $\left(1 / T_{1 p}{ }^{k}\right) /\left(1 / T_{1 p}{ }^{k}\right)$ to be $91 \%, 90 \%$, and $46 \%$ for $\mathrm{CO}_{2}, \mathrm{CH}$, and $\mathrm{CH}_{3}$, respectively, where we included $\mathrm{Cu}(\mathrm{II})$ within $10 \AA$ from ${ }^{13} \mathrm{C}$ of interest in this calculation. Similarly, for $\mathrm{Mn}(\mathrm{acac})_{3}$, the estimated values of $\left(1 / T_{1 p}{ }^{k}\right) /\left(1 / T_{1 p}{ }^{k}\right)$ were $97 \%-98 \%, 90 \%-$ $94 \%$, and $50 \%-63 \%$ for $\mathrm{CO}, \mathrm{CH}$, and $\mathrm{CH}_{3}$, respectively. 
TABLE I. Relative metal- ${ }^{13} \mathrm{C}$ distances estimated from ${ }^{13} \mathrm{C} T_{1 p}$ values and $\mathrm{x}$-ray structure for $\mathrm{Cu}(\mathrm{DL}-\mathrm{Ala})_{2}$ and $\operatorname{Mn}(\mathrm{acac})_{3}$.

\begin{tabular}{|c|c|c|c|c|c|c|c|}
\hline Sample & $\begin{array}{l}\text { Chemical } \\
\text { group }\end{array}$ & $\begin{array}{l}{ }^{13} \mathrm{C} T_{1 p} \\
(\mathrm{~ms})^{\mathrm{a}}\end{array}$ & $\begin{array}{c}{ }^{13} \mathrm{C} \delta_{\text {iso }} \\
(\mathrm{ppm})\end{array}$ & $\left(R / R_{\mathrm{CO}}\right)_{T 1}{ }^{\mathrm{b}}$ & $\left(R / R_{\mathrm{CO}}\right)_{\mathrm{x}-\mathrm{ray}} \mathrm{c}$ & $R_{T 1}(\AA)^{\mathrm{d}}$ & $R_{\mathrm{x} \text {-ray }}(\AA)$ \\
\hline \multirow[t]{3}{*}{$\mathrm{Cu}(\mathrm{DL}-\mathrm{Ala})_{2}$} & $\mathrm{CO}_{2}$ & $8.7 \pm 0.1$ & -192 & $\cdots$ & 1 & $\cdots$ & 2.74 \\
\hline & $\mathrm{CH}$ & $13.9 \pm 0.3$ & -277 & $1.08 \pm 0.005$ & 1.02 & $2.97 \pm 0.01$ & 2.81 \\
\hline & $\mathrm{CH}_{3}$ & $50.4 \pm 1.9$ & 172 & $1.34 \pm 0.009$ & 1.57 & $3.67 \pm 0.03$ & 4.18 \\
\hline \multirow[t]{8}{*}{$\operatorname{Mn}(\mathrm{acac})_{3}$} & \multirow{4}{*}{$\mathrm{CO}$} & $1.2 \pm 0.1$ & 517 & $\cdots$ & \multirow{4}{*}{$1-1.02$} & $\cdots$ & \multirow{4}{*}{$2.86-2.93$} \\
\hline & & $1.5 \pm 0.5$ & 1298 & $1.04 \pm 0.05$ & & $2.97 \pm 0.16$ & \\
\hline & & $2.7 \pm 0.6$ & 848 & $1.14 \pm 0.05$ & & $3.26 \pm 0.13$ & \\
\hline & & $4.0 \pm 0.5$ & 110 & $1.22 \pm 0.03$ & & $3.48 \pm 0.08$ & \\
\hline & $\mathrm{CH}$ & $3.4 \pm 0.1$ & 349 & $1.18 \pm 0.01$ & $1.13-1.16$ & $3.38 \pm 0.04$ & $3.23-3.31$ \\
\hline & \multirow{3}{*}{$\mathrm{CH}_{3}$} & $6.5 \pm 0.4$ & -560 & $1.32 \pm 0.02$ & \multirow{3}{*}{$1.46-1.51$} & $3.77 \pm 0.06$ & \multirow{3}{*}{$4.25-4.33$} \\
\hline & & $11.0 \pm 0.3$ & -122 & $1.44 \pm 0.02$ & & $4.12 \pm 0.05$ & \\
\hline & & $11.5 \pm 0.4$ & -57 & $1.45 \pm 0.02$ & & $4.15 \pm 0.05$ & \\
\hline
\end{tabular}

${ }^{a}$ For the $\mathrm{CH}_{3}$ groups, we corrected the $T_{1 p}$ values using $1 / T_{1 p}=1 / T_{1}-1 / T_{1 \text { dia }}$, where we adopted $T_{1 \text { dia }}$ $=75 \pm 2 \mathrm{~ms}$, which was obtained for $L$-Ala.

${ }^{\mathrm{b}}\left(R / R_{\mathrm{CO}}\right)_{T 1}=\left[\left(T_{1 p} \text { for the corresponding }{ }^{13} \mathrm{C}\right) /\left(T_{1 p} \text { for } \mathrm{CO}_{2}{ }^{-} \text {or } \mathrm{CO}\right)\right]^{1 / 6}$ For $\mathrm{Mn}(\mathrm{acac})_{3}$, the shortest $T_{1}$ for ${ }^{13} \mathrm{CO}$ of $1.2 \mathrm{~ms}$ was selected as the reference.

${ }^{c}$ The values denote the range of relative distances between the metal center and crystallographically nonequivalent carbons for the same chemical groups. $R_{\mathrm{CO}}=2.74$ and $2.86 \AA$ for $\mathrm{Cu}(\mathrm{DL}-\mathrm{Ala})_{2}$ and $\mathrm{Mn}(\mathrm{acac})_{3}$, respectively. ${ }^{\mathrm{d}} R_{T 1}=\left(R / R_{\mathrm{CO}}\right)_{T 1}\left(R_{\mathrm{CO}}\right)_{\mathrm{x} \text {-ray }}$, where $\left(R_{\mathrm{CO}}\right)_{x \text {-ray }}$ is the same as $R_{\mathrm{CO}}$ defined in c.

Hence, the intercomplex contribution to the $T_{1}$ values is not negligible for the ${ }^{13} \mathrm{C}$ having a longer intracomplex distance to a metal (i.e., for ${ }^{13} \mathrm{CH}_{3}$ groups in the above case). On the other hand, because of the $R^{6}$ dependence of $T_{1 p}$, for example, $50 \%$ of the intercomplex contribution shortens the estimated distance by only $12 \%$. This intercomplex relaxation effect well explains that $R_{T 1}$ estimated from $T_{1 p}$ in Table I are slightly shorter for $\mathrm{CH}_{3}$ than those from x-ray diffraction $\left(R_{\mathrm{x} \text {-ray }}\right)$. Thus, relatively accurate distances were obtained from the simple analysis of ${ }^{13} \mathrm{C} T_{1}$ values without including the intercomplex effects. In larger molecules, the intercomplex relaxation effect will be less because the density of paramagnetic metal ions is lower. Although only relative distances can be measured by this method, a set of absolute distances can be determined by combining the relative distances with one absolute distance determined from a measurement of ${ }^{13} \mathrm{C}$ anisotropic hyperfine shifts, as will be discussed in the next section.

It is also noteworthy that when $R$ and $S$ are known, the electron spin correlation time $\tau_{S}$ can be estimated from Eq. (3). For $\mathrm{Cu}(\mathrm{DL}-\mathrm{Ala})_{2}$, we obtained $\tau_{S}=1.1 \times 10^{-11} \mathrm{~s}$ from $T_{1}$ of $8.7 \mathrm{~ms}$ for ${ }^{13} \mathrm{CO}_{2}^{-}$. The inverse of this value $\left(9.1 \times 10^{10} \mathrm{~Hz}\right)$ agreed well with electron-electron spin coupling constant $2 J \sim 6.7 \times 10^{10} \mathrm{~Hz}$ estimated from heat measurements at low temperatures $(2-50 \mathrm{~K}) .{ }^{47}$ Thus, ${ }^{13} \mathrm{C} T_{1} \mathrm{SS}$ NMR measurements in paramagnetic systems provide a way to estimate electron spin couplings, which are sensitive to metal-metal distances. For $\mathrm{Mn}(\mathrm{acac})_{3}$, for which $2 \mathrm{~J}$ or EPR line shape is unknown, the present SSNMR data yielded $\tau_{S}$ $\sim 1 \times 10^{-11} \mathrm{~s}$ from ${ }^{13} \mathrm{C} T_{1}$ of ${ }^{13} \mathrm{CO}(1.2 \mathrm{~ms})$ and the known $\mathrm{Mn}-{ }^{13} \mathrm{CO}$ distance $(2.86 \AA)$. It is quite interesting that ${ }^{13} \mathrm{C}$ SSNMR can provide information on the electron spin correlation time $\tau_{S}$ for this sample, for which EPR analysis has not been effective. $^{49}$

\section{B. Metal- ${ }^{13} \mathrm{C}$ distance from anisotropic hyperfine shifts}

It has been reported that anisotropic hyperfine shifts observed in ${ }^{13} \mathrm{C}$ and ${ }^{2} \mathrm{D}$ SSNMRs provide useful information on ${ }^{13} \mathrm{C}-M$ distances $(R)$ for selectively ${ }^{13} \mathrm{C}$ - and/or ${ }^{2} \mathrm{D}$-labeled paramagnetic systems. ${ }^{16,50} \mathrm{As}{ }^{13} \mathrm{C} T_{1}$ measurements, $1 / R^{3}$ dependence of the anisotropic hyperfine shifts has been rarely utilized for SSNMR of unlabeled paramagnetic systems because of the difficulty in signal assignment and the limited sensitivity/resolution. We recently examined the effectiveness of this strategy in ${ }^{13} \mathrm{C}$ SSNMR for unlabeled paramagnetic systems, based on the signal assignment available from the VFMAS approach. ${ }^{26}$ In this section, we provide additional data that confirm the effectiveness.

Table II shows ${ }^{13} \mathrm{C}$ anisotropic shifts for $\mathrm{Cu}(\mathrm{DL}-\mathrm{Ala})_{2}$ and $\mathrm{Mn}(\mathrm{acac})_{3}$ obtained from spinning sideband analysis of ${ }^{13} \mathrm{C}$ MAS spectra. Following the work by Antzutkin et al., ${ }^{51}$ we defined a span of the anisotropic hyperfine shift, $\Delta_{\text {aniso, as }}$ $\sigma_{z z}-\sigma_{\text {iso }}=\Delta \sigma_{z z}$, where $\left|\Delta \sigma_{z z}\right|>\left|\Delta \sigma_{x x}\right|>\left|\Delta \sigma_{y y}\right|$ and $\Delta \sigma_{k k}$ $=\sigma_{k k}-\sigma_{\text {iso }}(k=x, y, z)$. The principal values for $\mathrm{Cu}(\mathrm{DL}-\mathrm{Ala})_{2}$ were obtained from sideband analysis using Herzfeld and Berger's method ${ }^{51,52}$ for the spectrum acquired under slow MAS $(5 \mathrm{kHz})$ with strong ${ }^{1} \mathrm{H}$ rf decoupling, which removed the effect of ${ }^{1} \mathrm{H}-{ }^{13} \mathrm{C}$ dipolar couplings. Although recoupling techniques under VFMAS may provide more accurate ${ }^{13} \mathrm{C}$ anisotropic shifts with improved resolution, in this study, we focused on confirming the feasibility of measuring distances from the anisotropic hyperfine shifts. For $\mathrm{Mn}(\mathrm{acac})_{3}$, the spinning sideband analysis was possible for the data obtained under VFMAS at $20 \mathrm{kHz}$ without decoupling, since ${ }^{1} \mathrm{H}-{ }^{13} \mathrm{C}$ dipolar couplings do not contribute to the spinning sideband patterns significantly because of the large hyperfine shift. For $\mathrm{CH}_{3}$ of $\mathrm{Cu}(\mathrm{DL}-\mathrm{Ala})_{2}$, the anisotropic shift was too small to be precisely determined by Herzfeld and Berger's method. 
TABLE II. Experimental ${ }^{13} \mathrm{C}$ anisotropic hyperfine shifts for ${ }^{13} \mathrm{C}$ spins of $\mathrm{Cu}(\mathrm{DL}-\mathrm{Ala})_{2}$ and $\mathrm{Mn}(\mathrm{acac})_{3}$ together with metal- ${ }^{13} \mathrm{C}$ distances determined from the data $\left(R_{\text {shift }}\right)$ and the x-ray crystal structure $\left(R_{\mathrm{x} \text {-ray }}\right)$ (Refs. 47 and 48).

\begin{tabular}{|c|c|c|c|c|c|c|}
\hline Sample & $S$ & $\begin{array}{c}\text { Chemical } \\
\text { group }\end{array}$ & $\begin{array}{c}{ }^{13} \mathrm{C} \delta_{\text {iso }} \\
(\mathrm{ppm})\end{array}$ & $\Delta_{\text {aniso }}{ }^{\mathrm{a}}(\mathrm{ppm})$ & $R_{\text {shift }}(\AA)^{\mathrm{b}}$ & $R_{\text {x-ray }}(\AA)$ \\
\hline \multirow{3}{*}{$\mathrm{Cu}(\text { DL-Ala })_{2}$} & \multirow{3}{*}{$\frac{1}{2}$} & $\mathrm{CO}_{2}^{-}$ & -240 & $-331 \pm 4$ & $2.33 \pm 0.01$ & 2.74 \\
\hline & & $\mathrm{CH}$ & -320 & $-149 \pm 10$ & $3.04 \pm 0.07$ & 2.81 \\
\hline & & $\mathrm{CH}_{3}$ & 190 & $53 \pm 2$ & $4.30 \pm 0.05$ & 4.18 \\
\hline \multirow[t]{5}{*}{$\operatorname{Mn}(\mathrm{acac})_{3}$} & \multirow{5}{*}{2} & $\mathrm{CO}$ & 611 & $744 \pm 27$ & $3.55 \pm 0.04$ & $2.98-3.02$ \\
\hline & & $\mathrm{CH}$ & 358 & $918 \pm 32$ & $3.38 \pm 0.04$ & $3.25-3.32$ \\
\hline & & \multirow{3}{*}{$\mathrm{CH}_{3}$} & -76 & $-421 \pm 15$ & $4.38 \pm 0.05$ & \multirow{3}{*}{$4.22-4.40$} \\
\hline & & & -137 & $464 \pm 18$ & $4.24 \pm 0.05$ & \\
\hline & & & -637 & $-310 \pm 21$ & $4.85 \pm 0.11$ & \\
\hline
\end{tabular}

${ }^{\mathrm{a} W h e n ~} \Delta_{\text {aniso }}>0, \sigma_{\mathrm{ZZ}}=\sigma_{11}$; when $\Delta_{\text {aniso }}<0, \sigma_{\mathrm{ZZ}}=\sigma_{33} . \Delta_{\text {aniso }}=\Delta \sigma_{\mathrm{ZZ}} \equiv \sigma_{\mathrm{ZZ}}-\sigma_{\text {iso }}$, where $\sigma_{\text {iso }}$ is the isotropic shift. In the ideal axially symmetric case, $\Delta_{\text {aniso }}=\Delta \sigma_{11}$ and $\Delta \sigma_{22}=\Delta \sigma_{33}=-\Delta \sigma_{11} / 2$, where $\Delta \sigma_{k k}=\sigma_{k k}-\sigma_{\text {iso }}$ and $\sigma_{11}$ $>\sigma_{22}>\sigma_{33}$.

${ }^{\mathrm{b}} \Delta_{\text {aniso }} \equiv\left|\delta_{z z}-\delta_{\text {iso }}\right| \equiv\left\{1.661 \times 10^{6} S(S+1)\right\} /\left(R^{3} T\right)(\mathrm{ppm})$ was used to obtain $R_{\text {shift }}$ with $T=297$ and $282 \mathrm{~K}$ for $\mathrm{Cu}(\mathrm{DL}-\mathrm{Ala})_{2}$ and $\mathrm{Mn}(\mathrm{acac})_{3}$, respectively.

For this system, we assumed the axial symmetry $\left(\sigma_{x x}=\sigma_{y y}\right)$ and determined the anisotropic shift, $\Delta_{\text {aniso }}$, from simulation of sideband patterns. In analysis of the anisotropic hyperfine shifts, we assumed an isotropic $g$-tensor and a point electron dipole at the metal center. We assume that the system has a relatively weak or negligible spin-orbit coupling interaction. The contribution of diamagnetic shifts was not included. For the simplified nuclear-electron spin dipolar interactions, $\Delta_{\text {aniso }}$ is given by ${ }^{16,17}$

$$
\left|\Delta_{\text {aniso }}\right|=2 c\left(\mu_{0} / 4 \pi R^{3}\right),
$$

where $c=g^{2} \mu_{B}^{2} S(S+1) / 3 k_{B} T, T$ is the temperature, $k_{B}$ is Boltzmann's constant, $\mu_{B}$ is the Bohr magneton, and $g$ is the isotropic value of the electron $g$-tensor. By substituting known constants in Eq. (7), ${ }^{2}$ we obtain $\left|\Delta_{\text {aniso }}\right|$ in units of ppm

$$
\left|\Delta_{\text {aniso }}\right|=\left\{1.661 \times 10^{6} S(S+1)\right\} /\left(R^{3} T\right)(\mathrm{ppm}),
$$

where we adopted the $g$ value of 2.0023 for a free electron spin $\left(g_{e}\right)$ and $R$ and $T$ are in units of $\AA$ and $\mathrm{K}$, respectively. Equations (7) and (8) are valid for any nuclear spins to be observed. When the experimental $g$ value is known, it is recommended using the $g$ value in place of $g_{e}$ in Eq. (8). The effects of the $g$-anisotropy on the distance measurements will be discussed elsewhere. The metal- ${ }^{13} \mathrm{C}$ distances estimated from this equation $\left(R_{\text {shift }}\right)$ and the experimental $\Delta_{\text {aniso }}$ are given in Table II, together with the corresponding x-ray distances, $R_{\mathrm{x} \text {-ray }}$.

In the above analysis, the pseudocontact shifts within a complex are considered as a primary source of paramagnetic anisotropic shifts. However, it is known that contributions from intercomplex hyperfine couplings are not negligible, particularly for small complexes. ${ }^{16}$ For $\mathrm{CO}_{2}{ }^{-}$or $\mathrm{CO}$ groups, their anisotropic diamagnetic chemical shifts are relatively large $\left(\left|\sigma_{33}-\sigma_{\text {iso }}\right| \sim 70 \mathrm{ppm}\right)$. For these reasons, the hyperfine shift tensors notably deviate from the axial symmetry. In spite of the substantial simplifications, $R_{\text {shift }}$ and $R_{\mathrm{x} \text {-ray }}$ agree reasonably well for $\mathrm{Cu}(\mathrm{DL}-\mathrm{Ala})_{2}$ and $\mathrm{Mn}(\mathrm{acac})_{3}$. The difference between $R_{\text {shift }}$ and $R_{\text {x-ray }}$ was within 0.48 and $0.50 \AA$ for $\mathrm{Cu}(\mathrm{DL}-\mathrm{Ala})_{2}$ and $\mathrm{Mn}(\mathrm{acac})_{3}$, respectively, where the maximum deviation was obtained for ${ }^{13} \mathrm{CO}_{2}^{-}$or ${ }^{13} \mathrm{CO}$. The reasonable agreement is consistent with the previous ${ }^{2}$ D SSNMR studies of anisotropic hyperfine shifts for selectively ${ }^{2} \mathrm{D}$-labeled paramagnetic systems including $\mathrm{Mn}(\text { acac-3-d })_{3}{ }^{50}$ For the $\mathrm{CH}$ groups, which are located relatively close to the metal centers in both compounds, the difference is within $0.22 \AA$. The modest deviation in the estimated distances is reasonable considering that $\left|\Delta_{\text {aniso }}\right|$ has $1 / R^{3}$ dependence, and that intercomplex pseudocontact shifts generally do not cancel out intracomplex shifts completely. As discussed in the Appendix, $\left|\Delta_{\text {aniso }}\right|$ is relatively insensitive to the effects of the intercomplex shifts. In contrast, the asymmetry parameter $\eta$ is very sensitive to the intercomplex shifts. Although intercomplex shifts are not negligible in general, ${ }^{16}$ it appears safe to estimate distances based on the anisotropic hyperfine shifts for ${ }^{13} \mathrm{C}$ located in close proximity to the metal center (i.e., ${ }^{13} \mathrm{C}$ having large hyperfine shifts), because intracomplex shifts are often dominant for such nuclei. Care should be exercised in the analysis of $R_{\text {shift }}$ when metal ions are likely to form a cluster. In such a case, it is possible that intercomplex paramagnetic anisotropic shifts are even larger than intracomplex shifts, and thus intercomplex couplings need to be explicitly considered. For molecules with known structures, information on supramolecular structures may be elucidated by quantitative analysis of $\eta$. If necessary, the effects of the intercomplex shifts may be partially removed by dilution of paramagnetic metals with equivalent diamagnetic metals. ${ }^{16}$

The obtained absolute distances from the analysis of $\left|\Delta_{\text {aniso }}\right|$ can be combined with relative distances estimated from ${ }^{13} \mathrm{C} T_{1}$ values for distance measurements. The combination is particularly useful because signal overlap often forbids resolving all the signals in ${ }^{13} \mathrm{C}$ SSNMR spectra in unlabeled systems. Because a few alternatives are available for elucidating structural constraints for unlabeled paramagnetic systems in noncrystalline solids, our strategy to obtain multiple distances from ${ }^{13} \mathrm{C} T_{1}$ and anisotropic hyperfine shifts in ${ }^{13} \mathrm{C}$ SSNMR provides a useful means of structural measure- 


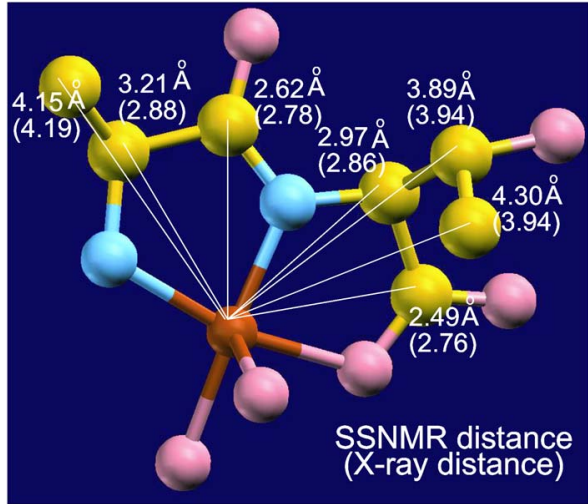

FIG. 7. (Color online) An x-ray structure of $\mathrm{Cu}(\mathrm{II})\left(\right.$ Ala-Thr) $\cdot \frac{1}{2} \mathrm{H}_{2} \mathrm{O}$ together with the distances between $\mathrm{Cu}$ and ${ }^{13} \mathrm{C}$ (thin white line) obtained from SSNMR experiments and those from the x-ray structure (Ref. 53) (in parentheses). The atoms are color coded in the online figure as follows: yellow $(\mathrm{C})$, blue $(\mathrm{N})$, red $(\mathrm{Cu})$, and pink $(\mathrm{O})$, where hydrogens are omitted.

ments for paramagnetic complexes, combined with the highresolution and reliable assignments obtained through the VFMAS approach.

By combination of the two approaches discussed in (A) and $(\mathrm{B})$, we recently determined all the seven distances ${ }^{26}$ between $\mathrm{Cu}(\mathrm{II})$ and ${ }^{13} \mathrm{C}$ for unlabeled $\mathrm{Cu}(\mathrm{Ala}-\mathrm{Thr})$, as shown in Fig. 7, which displays a comparison of the SSNMR distances with the X-ray distances. ${ }^{53}$ The SSNMR distance for $R_{\mathrm{CO}}$ (between $\mathrm{Cu}$ and ${ }^{13} \mathrm{CO}$ of Ala) was obtained from the pseudocontact shifts while the rest of the distances were obtained from the relative distances $\left(R_{j} / R_{\mathrm{CO}}\right)$ from ${ }^{13} \mathrm{C} T_{1 p}$ values. ${ }^{26}$ The SSNMR distances agreed reasonably well with the corresponding $\mathrm{X}$-ray distances within $12 \%$. It should be emphasized that the structural analysis was made possible with the assignments we obtained in Fig. 5.

\section{Elucidating polymorphs by evaluating ${ }^{13} \mathrm{C}$ experimental hyperfine shifts with ab initio calculation}

Paramagnetic systems are widely used as drugs and materials in solid forms. In pharmacology, characterization of different morphologies for drug compounds is essential because the morphologies modulate the bioavailability and stability of the drug. ${ }^{7,54}$ Morphologies in solid materials are known to alter their properties. ${ }^{55}$ In this section, we discuss our recent applications of the VFMAS approach for examination of polymorphologies in paramagnetic systems.

Figures $8(\mathrm{a})$ and $8(\mathrm{c})$ show ${ }^{13} \mathrm{C}$ VFMAS spectra of (a) $\alpha$-form and (c) $\beta$-form of $\mathrm{Cu}(8 \text {-quinolinol })_{2}\left(\mathrm{CuQ}_{2}\right)$ with corresponding molecular structures. Assignments to chemical groups were obtained by the ${ }^{13} \mathrm{C}-{ }^{1} \mathrm{H}$ REDOR method. $\mathrm{CuQ}_{2}$ has been studied as an antileukemia agent, ${ }^{56}$ and its $\beta$-form is thermally more stable. ${ }^{57}$ Thus, we used the system as a suitable model for demonstrating the feasibility of distinguishing polymorphs in a drug compound by SSNMR. The $\alpha$-form shows an interesting molecular-chain-like supramolecular structure as shown in the inset in Fig. 8(a), while the $\beta$-form has a dimerlike structure in Fig. 8(c). For both forms, the VFMAS spectra show excellent resolution. Clearly, the two polymorphs of this complex can be distin-
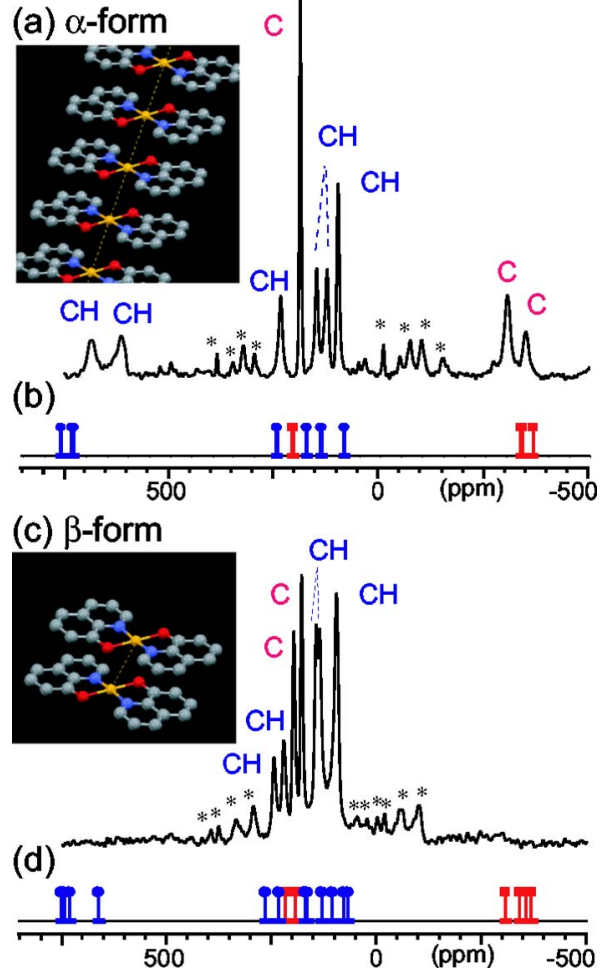

FIG. 8. (Color online) [(a) and (c) ${ }^{13} \mathrm{C}$ MAS spectra of (a) $\alpha$-form and (c) $\beta$-form $\mathrm{Cu}(8 \text {-quinolinol })_{2}\left(\mathrm{CuQ}_{2}\right)$ obtained at ${ }^{13} \mathrm{C}$ frequency of $100.6 \mathrm{MHz}$ without decoupling under VFMAS at $20 \mathrm{kHz}$ with corresponding x-ray structures (Ref. 57). The experimental time was (a) 21 and (c) $42 \mathrm{~min}$ for $15 \mathrm{mg}$ of the samples. Spinning sidebands are indicated by ${ }^{*}$. Atoms in the structures are color coded: $\mathrm{C}$ (gray), $\mathrm{N}$ (blue), $\mathrm{O}$ (red), and $\mathrm{Cu}$ (orange); the $\mathrm{Cu}-\mathrm{Cu}$ distances are (a) 3.84 and (c) $3.44 \AA$. [(b) and (d)] Shift positions obtained by $a b$ initio calculations for (b) $\alpha-\mathrm{CuQ}_{2}$ and (d) $\beta-\mathrm{CuQ}_{2}$ in the tetrameric forms. The positions of the predicted shifts for $\mathrm{CH}$ and nonprotonated carbons are indicated by filled circles (blue) and squares (red), respectively. See Ref. 27 about the details of the experiments and the ab initio calculations.

guished from the ${ }^{13} \mathrm{C}$ VFMAS spectra collected in $1 \mathrm{~h}$ for small amounts of the unlabeled samples $(\sim 15 \mathrm{mg})$.

Because an $\alpha-\mathrm{CuQ}_{2}$ complex has a very similar structure to a $\beta-\mathrm{CuQ}_{2}$ complex $(\mathrm{RMSD}=0.179 \AA)$, the significant difference in the spectral features should be attributed to paramagnetic effects. To confirm this, as shown in Figs. 8(b) and $8(\mathrm{~d})$, we carried out ab initio calculations of the shifts ${ }^{21,22}$ for 6 nonprotonated ${ }^{13} \mathrm{C}$ (red bar with square) and $12{ }^{13} \mathrm{CH}$ (blue bar with circle) in (b) $\alpha$ - and (d) $\beta-\mathrm{CuQ}_{2}$. Recent studies reported that $a b$ initio calculations of ${ }^{13} \mathrm{C}$ shifts are effective for paramagnetic systems in solids. ${ }^{21,22}$ Although the calculated diamagnetic shifts show only small difference of $1.9 \mathrm{ppm}$ in absolute values on average between the two forms, the two polymorphs clearly present distinctive calculated hyperfine shifts ( $\sim 15 \mathrm{ppm}$ on average). This confirms that hyperfine shifts are exceptionally sensitive to small structural differences between the two polymorphs. In (d), more lines are predicted than in (b), reflecting that two Q's are equivalent in $\alpha-\mathrm{CuQ}_{2}$, but the symmetry is reduced in $\beta$ - $\mathrm{CuQ}_{2} .{ }^{27}$ The calculations for the $\beta$-form (d) show the presence of the peaks around 650 and $-350 \mathrm{ppm}$. However, these peaks are not observed in Fig. 8(c) probably because of enhanced paramagnetic relaxation, as described below. Because in $\alpha-\mathrm{CuQ}_{2}$ the corresponding signals show considerably 


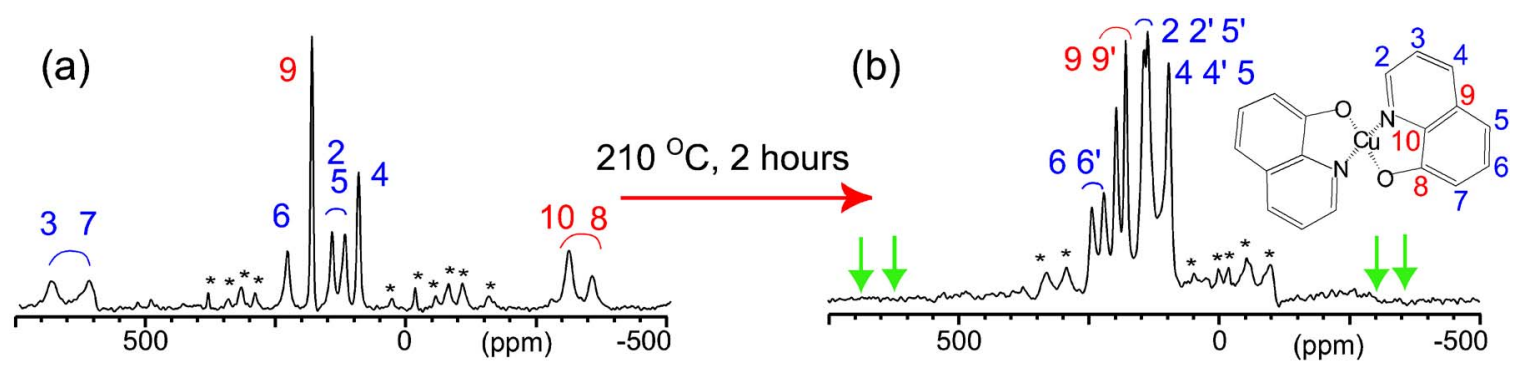

FIG. 9. (Color online) [(a) and (b)] ${ }^{13} \mathrm{C}$ MAS spectra of (a) $\alpha-\mathrm{CuQ}_{2}$ and (b) $\beta-\mathrm{CuQ}_{2}$ obtained by heating $\alpha-\mathrm{CuQ}_{2}$ at $210{ }^{\circ} \mathrm{C}$ for $2 \mathrm{~h}$, with $a b$ initio based assignments. $n$ denotes the site indicated in the inset $(n=2-10) ; n^{\prime}$ is the corresponding site in the nonequivalent $\mathrm{Q}$ in $\beta$-CuQ ${ }_{2}$. The spinning speeds were $20.0 \mathrm{kHz}$; the experimental time was (a) 21 and (b) $86 \mathrm{~min}$.

shorter $T_{2}(0.2-0.4 \mathrm{~ms})$ than signals at $50-300 \mathrm{ppm}$ $(0.8-3.2 \mathrm{~ms})$, and the $\beta$-form has shorter $T_{2}$ for the signals in the latter region $(0.4-1.2 \mathrm{~ms})$, the missing signals in $\beta-\mathrm{CuQ}_{2}$ are likely to be quenched by the enhanced paramagnetic relaxation.

In Figs. 9(a) and 9(b), we demonstrated that this VFMAS approach can be used for characterizing a solid-state thermal reaction of $\alpha-\mathrm{CuQ}_{2}$ in which $\alpha-\mathrm{CuQ}_{2}$ was heated for $2 \mathrm{~h}$ in a crucible in a sand bath. ${ }^{27}$ The assignments in Figs. 9(a) and 9(b) were obtained from a comparison of the $a b$ initio calculations with the experimental shifts. The spectrum of the reaction product in Fig. 9(b) is nearly identical to the spectrum in Fig. 8(c) for $\beta-\mathrm{CuQ}_{2}$. More quantitative analysis of using the spectra in Figs. 8(a) and 8(c) as reference spectra showed that the product is $\beta-\mathrm{CuQ}_{2}$ with purity of $95 \%$ or higher. Our additional study showed that SSNMR analysis provides quantitative information on polymorphs when multiple polymorphs coexist in a sample. ${ }^{27}$

\section{APPLICATIONS OF PARAMAGNETIC SSNMR TO BIOMOLECULES}

Recent success in applications of paramagnetic interactions for biomolecular solution NMR (Refs. 2 and 58) and our progress in SSNMR studies of paramagnetic systems ${ }^{19,20,25,26}$ have stimulated SSNMR studies of paramagnetic biomolecules. Jovanovic and McDermott ${ }^{15}$ and Pintacuda et al. ${ }^{32}$ demonstrated excellent resolution in 2D ${ }^{13} \mathrm{C} /{ }^{13} \mathrm{C}$ or ${ }^{13} \mathrm{C} /{ }^{15} \mathrm{~N}$ correlation SSNMR spectra of ${ }^{13} \mathrm{C}$ - and ${ }^{15} \mathrm{~N}$-labeled paramagnetic metalloproteins such as cytochrome $\mathrm{P} 450 \mathrm{BM}-3$ and $\mathrm{Cu}(\mathrm{II})-\mathrm{Zn}(\mathrm{II})$ superoxide dismutase. Balayssac et al. recently showed that long-range distances (over $10 \AA$ ) can be elucidated for paramagnetic metalloproteins in solids. ${ }^{34}$ In these studies, however, SSNMR signals near the metal center $(R \leqslant 5 \AA)$ have not been observed, presumably because a traditional CPMAS approach was used in these studies. SSNMR methods for small unlabeled paramagnetic compounds using VFMAS can serve as a basis of methodologies to examine metal binding structures in paramagnetic metalloproteins. It is also noteworthy that use of paramagnetic interactions in nonparamagnetic biomolecular SSNMR becomes a powerful approach. Buffy et al. have utilized the paramagnetic broadening on ${ }^{13} \mathrm{C}$ linewidths to measure distances of ${ }^{13} \mathrm{C}$ sites in membrane bound peptides from the membrane surface with $\mathrm{Mn}$ (II) doping in water phase. ${ }^{59}$ Nadaud et al. recently used spin labeling to obtain long-range distance constraints. ${ }^{33}$ Our group recently proposed an approach to improve sensitivity in ${ }^{13} \mathrm{C}$ SSNMR for nonparamagnetic proteins with paramagnetic ion doping by acquiring signals with unusually short recycle delays that are matched to ${ }^{1} \mathrm{H} T_{1}$ values $(50-100 \mathrm{~ms})$ reduced by paramagnetic relaxation enhancement. ${ }^{35}$ We briefly outline this approach here at the end of this review.

Figure 10 shows ${ }^{13} \mathrm{C}$ CPMAS spectra of microcrystals of $\left[(\mathrm{a})\right.$ and (b)] lysozyme and $\left[(\mathrm{c})\right.$ and (d)] ubiquitin in $\mathrm{D}_{2} \mathrm{O}[(\mathrm{a})$ and (c)] with and [(b) and (d)] without $10 \mathrm{mM}$ $\mathrm{Cu}(\mathrm{II}) \mathrm{Na}_{2}$ EDTA complex (Cu-EDTA). The recycle delays were set to three times ${ }^{1} \mathrm{H} T_{1}$. The spectra were collected with common experimental times of [(a) and (b)] $2 \mathrm{~h}$ and $[(c)$ and (d)] 4 h. For comparison, the spectra were scaled so that the spectra for the same protein display a common noise level. It was found that $\mathrm{Cu}$-EDTA doping reduces ${ }^{1} \mathrm{H} T_{1}$ values of the proteins from $0.5-0.8 \mathrm{~s}$ to $\sim 60 \mathrm{~ms}$ by a factor of 8-13, allowing for substantial acceleration of the ${ }^{13} \mathrm{C} \mathrm{SS}-$ NMR experiments with the fast repetition approach. Thus, the spectra in Figs. 10(a) and 10(c) show significant sensitivity enhancements by a factor of 2.7-2.9, compared with those obtained without Cu-EDTA in (b) and (d). In order to avoid sample heating, we introduced rotor-synchronous $\pi$-pulse decoupling at a spinning speed of $40 \mathrm{kHz}$ in these experiments. ${ }^{35}$ For heat sensitive samples, it is recommended
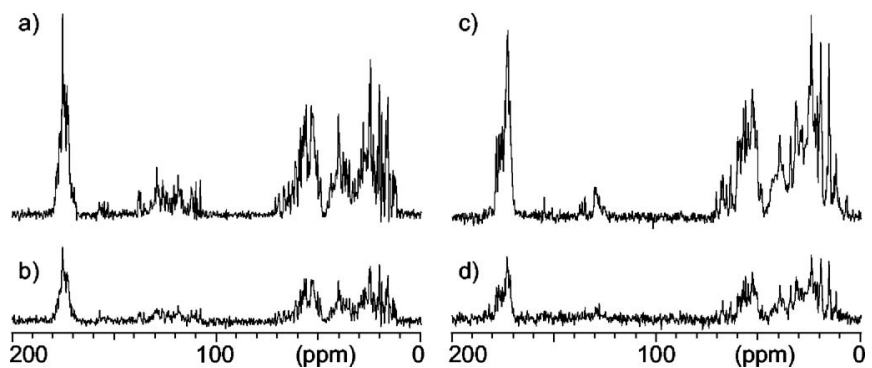

FIG. 10. ${ }^{13} \mathrm{C}$ CPMAS spectra of protein microcrystals for [(a) and (b)] lysozyme and [(c) and (d)] ubiquitin prepared in $\mathrm{D}_{2} \mathrm{O}$ obtained [(a) and (c)] with and [(b) and (d)] without $10 \mathrm{mM} \mathrm{Cu}-\mathrm{EDTA}$ at ${ }^{13} \mathrm{C}$ NMR frequency of 100.6 MHz. The recycle delays were (a) 0.18 , (b) 1.50 , (c) 0.18 , and (d) $2.50 \mathrm{~s}$. The spectra were acquired at a spinning speed of $40 \mathrm{kHz}$ with $\pi$-pulse-train decoupling with XY-8 phase cycle. In the decoupling scheme, a $\pi$-pulse with the width of $2.5 \mu$ s was rotor synchronously applied at the end of every rotor cycle $(25 \mu \mathrm{s})$. Signals were accumulated during acquisition periods of $20 \mathrm{~ms}$ with (a) 36000 , (b) 4800 , (c) 72000 , and (d) 5680 scans in a common total experimental time of [(a) and (b)] 2 or [(c) and (d)] $4 \mathrm{~h}$ at $-5{ }^{\circ} \mathrm{C}$. During the $\mathrm{CP}$ period of $1.0 \mathrm{~ms}$, the ${ }^{13} \mathrm{C}$ rf field was swept from 53 to $71 \mathrm{kHz}$, while the ${ }^{1} \mathrm{H}$ rf field was kept at $102 \mathrm{kHz}$. All the spectra were processed with Gaussian line broadening of $15 \mathrm{~Hz}$. 
to use the low-power two pulse phase modulation (TPPM) decoupling sequence, which we developed to attain more efficient decoupling with weak ${ }^{1} \mathrm{H}$ rf irradiation at $\mathrm{rf}$ intensity of $\sim 10 \mathrm{kHz}$ in the fast spinning condition. ${ }^{60}$ Further applications of this method in more advanced $2 \mathrm{D}$ and threedimensional experiments will be demonstrated in our future studies.

\section{CONCLUSION}

In this review, we demonstrated that VFMAS provides unprecedentedly high sensitivity and excellent resolution in both ${ }^{1} \mathrm{H}$ and ${ }^{13} \mathrm{C}$ SSNMR for a broad range of paramagnetic systems. Experimental results showed that ${ }^{1} \mathrm{H}$ SSNMR spectra under VFMAS at $24-28 \mathrm{kHz}$ display enhanced sensitivity by a factor of $12-18$, compared with the sensitivity under moderate MAS at $10 \mathrm{kHz}$, for $\mathrm{Cu}(\mathrm{DL}-\mathrm{Ala})_{2}$ and $\mathrm{Mn}(\mathrm{acac})_{3}$. We confirmed that the sensitivity of ${ }^{1} \mathrm{H}$ VFMAS spectra for paramagnetic systems can be 10-30 fold greater than that of diamagnetic systems. We also demonstrated that the VFMAS approach provides a foundation for a variety of methodologies such as polarization transfer, signal assignments by recoupling, and 2D correlation NMR, which have been long unattainable without isotope labeling in ${ }^{13} \mathrm{C}$ and ${ }^{1} \mathrm{H}$ SSNMR of paramagnetic systems. With the excellent sensitivity and resolution together with reliable signal assignments, we demonstrated methods of elucidating multiple distance constraints in unlabeled paramagnetic systems by combing SSNMR measurements of ${ }^{13} \mathrm{C} \quad T_{1}$ values and anisotropic hyperfine shifts. We also discussed an application of VFMAS SSNMR for distinguishing polymorphs by evaluating ${ }^{13} \mathrm{C}$ experimental hyperfine shifts in comparison with $a b$ initio chemical-shift calculations for the $\alpha$-form and $\beta$-form of $\mathrm{Cu}(8 \text {-quinolinol })_{2}$. Finally we introduced applications of paramagnetically enhanced relaxation to improve sensitivity in ${ }^{13} \mathrm{C}$ SSNMR of ubiquitin and lysozyme by recycling experiments with unusually short delays $(\sim 60 \mathrm{~ms})$, which are matched to short ${ }^{1} \mathrm{H} T_{1}$ values in the presence of doped paramagnetic ions. It is most likely that the VFMAS approaches presented here can be applied to a wide variety of paramagnetic and nonparamagnetic systems, including biomolecules.

\section{MATERIAL AND METHODS}

\section{A. Sample preparation}

$\mathrm{Cu}(\mathrm{II})(\text { DL-Ala })_{2} \cdot\left(\mathrm{H}_{2} \mathrm{O}\right), \quad \mathrm{Cu}(\mathrm{II})($ Ala-Thr $) \cdot 1 / 2\left(\mathrm{H}_{2} \mathrm{O}\right)$, and $\mathrm{Cu}$ (II)(8-quinolinol) $)_{2}$ were prepared following Refs. 14, 53, and 61, respectively. All the materials required for the synthesis were purchased from Sigma-Aldrich Co. (St. Louis, MO). L-Ala, $\mathrm{Cu}(\mathrm{II})(\mathrm{Gly})_{2}, \quad \mathrm{~V}(\mathrm{III})(\mathrm{acac})_{3}$, and $\mathrm{Mn}(\mathrm{III})(\mathrm{acac})_{3}$ used for the measurement were also purchased from Sigma Aldrich Co. Ubiquitin and lysozyme microcrystals were prepared following Ref. 62 with minor modification. ${ }^{35}$

\section{B. Solid-state NMR spectroscopy and experimental aspects}

All the SSNMR spectra were acquired at 9.4 T (400 and $100 \mathrm{MHz}$ for ${ }^{1} \mathrm{H}$ and ${ }^{13} \mathrm{C}$ NMR, respectively) with a Varian
Infinityplus $400 \mathrm{NMR}$ spectrometer using a Varian $3.2 \mathrm{~mm}$ MAS double-resonance T3 NMR probe and a homebuilt $2.5 \mathrm{~mm}$ MAS double-resonance probe except for the spectra in Figs. 6 and 10, which were collected using a $1.8 \mathrm{~mm}$ MAS double-resonance probe developed at Dr. Ago Samoson's Laboratory at National Institute of Chemical Physics and Biophysics, Estonia. The 3.2, 2.5, and $1.8 \mathrm{~mm}$ MAS probes provide a stable spinning up to 24,28 , and $40 \mathrm{kHz}$, respectively. All the data were processed with Varian Spinsight software or NMRPipe software. ${ }^{63}$

For the single $\pi / 2$-pulse excitation experiments in ${ }^{13} \mathrm{C}$ SSNMR, a rotor-synchronous echo sequence was used. In this sequence, a signal was excited by a $\pi / 2$-pulse and then acquired after two rotation periods, at the middle of which a $\pi$-pulse was applied in order to refocus large isotropic chemical shifts in paramagnetic complexes. Since the spectral width of the paramagnetic complexes is large (up to $200 \mathrm{kHz}$ at $9.4 \mathrm{~T}$ ), it is difficult to obtain a flat baseline without the echo sequence. For ${ }^{13} \mathrm{C}$ NMR, recycle times of the single pulse excitation experiments were set to three times ${ }^{13} \mathrm{C} T_{1}$ values or $M_{\text {dec }}$ times a ${ }^{1} \mathrm{H}$ rf decoupling period, whichever is longer, where $M_{\mathrm{dec}}=100$ and 75 for the 3.2 and $2.5 \mathrm{~mm}$ MAS probes, respectively. The value $M_{\mathrm{dec}}$ was selected for protecting the probes from arcing. For polarization transfer with CP, a ramp CP (Ref. 64) or an adiabatic CP sequence $^{65}$ was used to compensate for variation of Hartmann-Hahn conditions for systems with different resonance offsets. In these sequences, ${ }^{13} \mathrm{C}$ rf field was swept from $\left(\omega_{1 \mathrm{CP}}-\delta_{\mathrm{CP}} / 2\right)$ to $\left(\omega_{1 \mathrm{CP}}+\delta_{\mathrm{CP}} / 2\right)$, while ${ }^{1} \mathrm{H}$ rf was kept constant. In the adiabatic sequence, rf field for ${ }^{13} \mathrm{C}$ follows the tangential shape given by $\omega_{1}(t)=\omega_{1 \mathrm{CP}}+\delta_{\mathrm{CP}}\left(\tan \left[\alpha\left(t / \tau_{\mathrm{ct}}\right.\right.\right.$ $-1 / 2)] /[2 \tan (\alpha / 2)])\left(0 \leqslant t \leqslant \tau_{\mathrm{ct}}\right)$ during a contact time $\tau_{\mathrm{ct}}$, where $\alpha=2.498 \mathrm{rad}$. In the $\mathrm{CP}$ experiment, the recycle time was set to $M_{\mathrm{dec}} \tau_{\mathrm{ct}}$. In the dipolar INEPT sequence, the recycle times were set to three times ${ }^{1} \mathrm{H} T_{1}$ values. See Ref. 25 about the pulse sequences.

Because paramagnetic-isotropic shifts have $1 / T$ dependence (Curie's law) in the high temperature approximation, ${ }^{66}$ a spinning speed and a rf duty factor were found to affect observed chemical shifts. Because of this, severe line broadening can be induced by the temperature distribution over a sample heated by fast spinning. To suppress the broadening, cooling air $\left(-10\right.$ to $\left.23{ }^{\circ} \mathrm{C}\right)$ was used at the flow rate of $140-160(\mathrm{ft})^{3} / \mathrm{h}$ using a Varian VT stack. It is recommended that the experimental conditions are optimized to minimize the thermal distribution using standard samples such as $\mathrm{Pb}\left(\mathrm{NO}_{3}\right)_{2}$ (Ref. 67) $\mathrm{Cu}$ (DL-Ala) $)_{2}$ for higher resolution. For experimental simplicity, we indicated the temperature of cooling air rather than that of a sample. Unless otherwise mentioned, cooling air at room temperature $\left(23^{\circ} \mathrm{C}\right)$ was used. The typical temperature difference between a sample and the cooling air $\Delta T$ was 4,11 , and $29^{\circ} \mathrm{C}$ for the $3.2 \mathrm{~mm}$ MAS probe with cooling air at $24{ }^{\circ} \mathrm{C}$ at spinning speeds of 10,15 , and $22 \mathrm{kHz}$, respectively. The temperature difference approximately followed the relationship $\Delta T=0.0607$ $\left(\omega_{R} / 2 \pi\right)^{2}$, where $\omega_{R} / 2 \pi$ is in a unit of $\mathrm{kHz}$. For the $2.5 \mathrm{~mm}$ MAS probe, $\Delta T$ is 4,24 , and $47{ }^{\circ} \mathrm{C}$ at $\omega_{R} / 2 \pi$ of 10,20 , and $28 \mathrm{kHz}$, following $\Delta T=0.0600\left(\omega_{R} / 2 \pi\right)^{2}$. 


\section{Solution NMR}

All the ${ }^{13} \mathrm{C}$ solution NMR spectra were acquired using a Bruker Avance spectrometer $\left({ }^{1} \mathrm{H} 400 \mathrm{MHz}\right)$ with a Bruker $5 \mathrm{~mm}$ beta borium borate probe. To obtain the maximum spectral bandwidth (1400 ppm), a signal was acquired without digital filtering in a sampling interval of $7 \mu \mathrm{s}$. All the data were processed with NMRPipe software. ${ }^{63}$ In each spectrum, a Gauss function of $100 \mathrm{~Hz}$ was applied as a window function prior to Fourier transform. The baseline rolling was corrected with a sixth order polynomial function. The sample was dissolved in $0.7 \mathrm{ml}$ of deuterated solvent and placed in a $5 \mathrm{~mm}$ standard NMR tube.

\section{APPENDIX: EFFECTS OF INTERCOMPLEX ${ }^{13} \mathrm{C}-M$ PSEUDOCONTACT SHIFTS IN DISTANCE MEASUREMENTS}

\section{Theoretical estimation of intercomplex pseudocontact shifts}

The spin interactions between an electron spin and a nuclear spin are characterized by a Fermi contact shift and a pseudocontact shift (dipolar shift). While the former interaction is isotropic, the latter is generally anisotropic. The spin Hamiltonian due to the pseudocontact shift can be given by

$$
H_{D}=\sigma_{d} \boldsymbol{B}_{0} \cdot D_{\mathrm{EN}} \cdot \boldsymbol{I},
$$

where $\boldsymbol{I}$ represents a nuclear spin angular momentum, $\sigma_{d}$ is a constant given by $c \mu_{0} / 4 \pi, c=g^{2} \mu_{B}^{2} S(S+1) /\left(3 k_{\mathrm{B}} T\right)$, and $\boldsymbol{B}_{0}$ denotes a static magnetic field vector. We assumed that an electron is localized at a paramagnetic metal center. $D_{\mathrm{EN}}$ is the electron-nuclear dipolar coupling tensor defined by its matrix element ( $\alpha, \beta=x, y$, or $z$ as follows):

$$
\left(D_{\mathrm{EN}}\right)_{\alpha \beta}=\left(1 / r^{3}\right)\left\{\delta_{\alpha \beta}-3\left(r_{\alpha} r_{\beta}\right) / r^{2}\right\},
$$

where $\boldsymbol{r}$ is a vector between a paramagnetic metal center and a nucleus of our interest $I$, and $r=|\boldsymbol{r}|$, and $r_{\alpha}$ is the $\alpha$-component of $\boldsymbol{r}(\alpha=x, y, z)$. When the shift is represented by the sum of two pseudocontact shifts from the same kind of metal ions, the effective shift tensor is given by

$$
S_{\mathrm{EN}}=\sigma_{d}\left(D_{\mathrm{EN}}{ }^{0}+D_{\mathrm{EN}}^{1}\right),
$$

where $D_{\mathrm{EN}}{ }^{0}$ and $D_{\mathrm{EN}}{ }^{1}$ are tensors due to intracomplex and intercomplex interactions, respectively. Using unitary matrix $V_{k}, D_{\mathrm{EN}}{ }^{k}(k=0,1)$ can be diagonalized as

$$
\sigma_{d} D_{\mathrm{EN}}{ }^{k}=d_{k} V_{k}\left(\begin{array}{ccc}
1 & 0 & 0 \\
0 & 1 & 0 \\
0 & 0 & -2
\end{array}\right) V_{k}^{-1},
$$

where $d_{k}=\sigma_{d} / R_{k}{ }^{3}$ and $\boldsymbol{R}_{0}$ and $\boldsymbol{R}_{1}$ are given by vectors between $I$ and $S$ for the intracomplex and intercomplex couplings, respectively. $S_{\mathrm{EN}}$ can be also diagonalized as

$$
S_{\mathrm{EN}}=T\left(\begin{array}{ccc}
\sigma_{3} & 0 & 0 \\
0 & \sigma_{2} & 0 \\
0 & 0 & \sigma_{1}
\end{array}\right) T^{-1},
$$

where $T$ is a unitary matrix, $\left|\sigma_{2}\right|<\left|\sigma_{3}\right|<\left|\sigma_{1}\right|$ and $\sigma_{2} \sigma_{3}>0$, and $\left|\sigma_{1}\right|$ is equivalent to $\left|\Delta \sigma_{Z Z}\right|$ or $\left|\Delta_{\text {aniso }}\right|$ from its definition.
TABLE III. Intercomplex shift dependence of the ${ }^{13} \mathrm{C}-M$ distance calculated from pseudocontact shifts for ${ }^{13} \mathrm{CH}_{3}$ in $\mathrm{Cu}$ (DL-Ala) ${ }_{2}$.

\begin{tabular}{lcccc}
\hline \hline Index $k$ & $r_{k}(\AA)^{\mathrm{a}}$ & $\begin{array}{c}\Delta_{\text {aniso }}{ }^{\prime} \\
(\mathrm{ppm})^{\mathrm{b}}\end{array}$ & $\eta^{\prime{ }^{\mathrm{b}}}$ & $\begin{array}{c}\text { Estimated } \\
r_{0}(\AA)\end{array}$ \\
\hline 0 & 4.19 & -57.6 & 0.001 & 4.19 \\
1 & 4.93 & -56.2 & 0.650 & 4.22 \\
2 & 5.5 & 55.2 & 0.579 & 4.24 \\
3 & 5.56 & 45.8 & 0.946 & 4.52 \\
4 & 5.62 & 48.8 & 0.887 & 4.42 \\
5 & 6.12 & 49.7 & 0.596 & 4.40 \\
6 & 6.61 & 43.7 & 0.726 & 4.59 \\
7 & 7.24 & 48.7 & 0.767 & 4.43 \\
8 & 7.53 & 45.8 & 0.837 & 4.52 \\
9 & 7.91 & 42.6 & 0.780 & 4.63 \\
\hline \hline
\end{tabular}

${ }^{\mathrm{a}} r_{k}$ denotes the $k$ th shortest ${ }^{13} \mathrm{C}-M$ distance from $\mathrm{Cu}(\mathrm{II})$ in neighboring molecules for a ${ }^{13} \mathrm{CH}_{3}$ group. $r_{0}$ denotes the intracomplex ${ }^{13} \mathrm{C}-\mathrm{Cu}$ distance. ${ }^{\mathrm{b}} \Delta_{\text {aniso }}{ }^{\prime}$ and $\eta^{\prime}$ were calculated by diagonalizing the added pseudocontact shift tensor using Eqs. (A3a), (A3b), and (A4).

Because $D_{\mathrm{EN}}{ }^{k}$ is traceless, $\sigma_{1}+\sigma_{2}+\sigma_{3}=0$. By calculating $\operatorname{Tr}\left(S_{\mathrm{EN}}^{2}\right)$, we obtain

$$
\begin{aligned}
\Sigma \sigma_{j}^{2}= & 6 d_{0}^{2}+6 d_{1}^{2}+2 \sigma_{d}^{2} \operatorname{Tr}\left(D_{\mathrm{EN}}{ }^{0} D_{\mathrm{EN}}{ }^{1}\right) \\
= & 6 d_{0}^{2}+6 d_{1}^{2}+2 \sigma_{d}^{2} \operatorname{Tr}\left\{\left(V_{0} D_{\mathrm{EN}}{ }^{0} V_{0}^{-1}\right)\right. \\
& \left.\times\left(V_{0} V_{1}^{-1} V_{1} D_{\mathrm{EN}}{ }^{1} V_{1}^{-1} V_{1} V_{0}{ }^{-1}\right)\right\} .
\end{aligned}
$$

Here, $V_{0} V_{1}^{-1}$ denotes a unitary matrix transferring the system from the principal axis frame for $D_{\mathrm{EN}}{ }^{1}$ to that for $D_{\mathrm{EN}}{ }^{0}$. $V_{0} V_{1}^{-1}$ can be represented by Euler transformation as

$$
V_{0} V_{1}^{-1}=R_{z}(\alpha) R_{y}(\beta) R_{z}(\gamma) .
$$

Using Eqs. (A3a), (A3b), and (A5), Eq. (A6) can be rewritten as

$$
\Sigma \sigma_{j}^{2}=6 d_{0}^{2}+6 d_{1}^{2}+2 d_{0} d_{1}\left(-3+9 \cos ^{2} \beta\right) .
$$

With this equation, we evaluate how the intercomplex interaction alters the principal value $\sigma_{1}$. Using $\sigma_{1}=-\left(\sigma_{2}+\sigma_{3}\right)$ and $\left|\sigma_{2}-\sigma_{3}\right|=\eta\left|\sigma_{1}\right|$, we obtain $\Sigma \sigma_{j}^{2}=(3+\eta) \sigma_{1}^{2} / 2$. With this equation and Eq. (A7),

$$
\sigma_{1}^{2}=\{2 /(3+\eta)\}\left\{6 d_{0}^{2}+6 d_{1}^{2}+2 d_{0} d_{1}\left(-3+9 \cos ^{2} \beta\right) .\right.
$$

The range of $\eta$ is $0 \leqslant \eta \leqslant 1$. From $d_{0} d_{1}>0$ and $0 \leqslant \eta \leqslant 1$,

$$
\sigma_{1}^{2} \leqslant 4\left(d_{0}^{2}+d_{1}^{2}+2 d_{0} d_{1}\right)=4\left(d_{0}+d_{1}\right)^{2},
$$

where the equation is valid when $\beta=0$ and $\eta=0$. This is the case, when $\mathbf{r}_{0}=\mathbf{r}_{1}$ or the two principal axis frames for $D_{\mathrm{EN}}{ }^{0}$ and $D_{\mathrm{EN}}{ }^{1}$ coincide. In such a case $\left|\sigma_{1}\right|=2\left|d_{0}+d_{1}\right|$. On the other hand, we can also deduce

$$
\begin{aligned}
\sigma_{1}^{2} & \geqslant\{12 /(3+\eta)\}\left(d_{0}{ }^{2}+d_{1}{ }^{2}-d_{0} d_{1}\right) \\
& \geqslant 9 d_{0}{ }^{2} / 4+3\left(d_{1}-d_{0} / 2\right)^{2},
\end{aligned}
$$

where the equation is valid when $\beta=\pi / 2$ and $\eta=1$. If we can assume the intracomplex interaction is stronger than intercomplex interaction, $R_{0}<R_{1}$. In such a case, the minimum of $\left|\sigma_{1}\right|$ is given by $\left|\sigma_{1}\right|=3 d_{0} / 2$ when $d_{1}=d_{0} / 2\left(R_{1}=1.26 R_{0}\right)$. Thus, $D_{\mathrm{EN}}{ }^{1}$ does not completely cancel out $D_{\mathrm{EN}}{ }^{0}$ even in the "worst" case. 
TABLE IV. Intercomplex shift dependence of the ${ }^{13} \mathrm{C}-M$ distance calculated from pseudocontact shifts for ${ }^{13} \mathrm{CH}_{3}$ in $\mathrm{Mn}(\mathrm{acac})_{3}$.

\begin{tabular}{lcccc}
\hline \hline Index $k$ & $r_{k}(\AA)^{\mathrm{a}}$ & $\begin{array}{c}\Delta_{\text {aniso }}{ }^{\prime} \\
(\mathrm{ppm})^{\mathrm{a}}\end{array}$ & ${\eta^{\prime}}^{\mathrm{a}}$ & $\begin{array}{c}\text { Estimated } r_{0} \\
(\AA)\end{array}$ \\
\hline 0 & $4.24 \mathrm{~A}$ & -442.3 & 0.000 & 4.24 \\
1 & $4.9 \mathrm{~A}$ & -483.8 & 0.493 & 4.12 \\
2 & $5.5 \mathrm{~A}$ & -382.9 & 0.289 & 4.45 \\
3 & $6.3 \mathrm{~A}$ & -314.0 & 0.533 & 4.76 \\
4 & $7.5 \mathrm{~A}$ & -311.4 & 0.293 & 4.77 \\
5 & $7.7 \mathrm{~A}$ & -274.2 & 0.549 & 4.98 \\
6 & $8.2 \mathrm{~A}$ & -260.4 & 0.304 & 5.06 \\
7 & $9.8 \mathrm{~A}$ & -253.4 & 0.259 & 5.11 \\
8 & $9.9 \mathrm{~A}$ & -272.5 & 0.230 & 4.99 \\
9 & $10.1 \mathrm{~A}$ & -291.4 & 0.248 & 4.88 \\
\hline \hline
\end{tabular}

${ }^{\mathrm{a}}$ See Table III about the definitions of $r_{k}, \Delta_{\text {aniso }}{ }^{\prime}$, and $\eta^{\prime}$.

From Eqs. (A9) and (A10), the effects of intercomplex pseudocontact shifts can be roughly estimated. For example, when $R_{1}=2 R_{0}, 0.817\left|2 d_{0}\right|<\left|\sigma_{1}\right| \leqslant 1.0625\left|2 d_{0}\right|$. This changes the estimated distance only be from $-3 \%$ to $7 \%$. When $R_{1}$ $=2^{1 / 3} R_{0} \sim 1.26 R_{0}, \quad 0.75\left|2 d_{0}\right| \leqslant\left|\sigma_{1}\right| \leqslant 1.5\left|2 d_{0}\right|$. Thus, even when $R_{1}$ is comparable to $R_{0}$, this alters the estimated distance only by $-13 \%$ to $10 \%$. On the other hand, $\eta$ can change from 0 to 1 in the latter case. In this sense, the largest principal value $\left|\sigma_{1}\right|$ is a relatively robust parameter available for estimating $R_{0}$ even without knowledge of the intercomplex tensor $D_{\mathrm{EN}}{ }^{1}$

\section{Intercomplex ${ }^{13} \mathrm{C}-M$ paramagnetic anisotropic shifts calculated from $x$-ray structures}

Tables III and IV show intercomplex pseudocontact shift dependence of the calculated pseudocontact shift $\Delta_{\text {aniso }}\left(\sigma_{3}\right)$ for ${ }^{13} \mathrm{CH}_{3}$ groups in $\mathrm{Cu}$ (DL-Ala) $)_{2}$ and $\mathrm{Mn}(\text { acac })_{3}$, respectively. To estimate the effects, we added pseudocontact shift tensors up to ten closest metal centers from the ${ }^{13} \mathrm{CH}_{3}$ and obtained the principal value with the maximum absolute value $\left(\sigma_{Z Z}\right)$ from the added tensor. The $\Delta_{\text {aniso }}{ }^{\prime}$ and $\eta^{\prime}$ in the tables denotes $\Delta_{\text {aniso }}\left(\right.$ or $\sigma_{\mathrm{ZZ}}$ ) and $\eta$ obtained from the added tensor. We estimated the ${ }^{13} \mathrm{C}$-metal distance, $r_{0}{ }^{\prime}$ from $\Delta_{\text {aniso }}{ }^{\prime}$ using Eq. (8) The effects were calculated only for the $\mathrm{CH}_{3}$ groups, since the intercomplex effects are likely to be the most significant for the chemical group. Nevertheless, it is clear that the effect of the intercomplex pseudocontact shifts on the estimated distance $r_{0}{ }^{\prime}$ is moderate, although the $\eta$ value substantially fluctuates by the added tensor.

${ }^{1}$ I. Bertini, Bioinorganic Chemistry (University Science Books, Mill Valley, CA, 1994); W. Kaim and B. Schwederski, Bioinorganic Chemistry: Inorganic Elements in the Chemistry of Life an Introduction Guide (Wiley, New York, 1994).

${ }^{2}$ I. Bertini, C. Luchinat, and G. Parigi, Solution NMR of Paramagnetic Molecules: Applications to Metallobiomolecules and Models, 1st ed. (Elsevier, Amsterdam, 2001).

${ }^{3}$ P. Thordarson, A. Marquis, and M. J. Crossley, Org. Biomol. Chem. 1, 1216 (2003); D. Sun, F. S. Tham, C. A. Reed, and P. D. W. Boyd, Proc. Natl. Acad. Sci. U.S.A. 99, 5088 (2002); M. C. Feiters, A. E. Rowan, and R. J. M. Nolte, Chem. Soc. Rev. 29, 375 (2000); J. Okuda, J. Wakai, and K. Sode, Anal. Lett. 35, 1465 (2002); F. B. Wang, H. J. Jiang, W. Xing, T. H. Lu, and H. L. Chen, Acta Phys.-Chim. Sin. 18, 404 (2002); H. X. Ju, S. Q. Liu, B. X. Ge, F. Lisdat, and F. W. Scheller, Electroanalysis 14, 141 (2002); S. Yabuki, F. Mizutani, and Y. Hirata, Electrochemistry (To- kyo, Jpn.) 68, 853 (2000); K. V. Gobi and F. Mizutani, Sens. Actuators B 80, 272 (2001); T. Tatsuma and T. Watanabe, Anal. Chem. 63, 1580 (1991).

${ }^{4}$ T. Tanaka and F. Toda, Chem. Rev. (Washington, D.C.) 100, 1025 (2000).

${ }^{5}$ N. Farrell and Royal Society of Chemistry (Great Britain), Uses of Inorganic Chemistry in Medicine (Royal Society of Chemistry, Cambridge, 1999); M. Galanski, V. B. Arion, M. A. Jakupec, and B. K. Keppler, Curr. Pharm. Des. 9, 2078 (2003); C. X. Zhang and S. J. Lippard, Curr. Opin. Chem. Biol. 7, 481 (2003); K. H. Thompson and C. Orvig, Science 300 , 936 (2003); M. J. Abrams and B. A. Murrer, ibid. 261, 725 (1993).

${ }^{6}$ G. A. Stephenson, J. G. Stowell, P. H. Toma, D. E. Dorman, J. R. Greene, and S. R. Byrn, J. Am. Chem. Soc. 116, 5766 (1994); S. D. Clas, Curr. Opin. Drug Disc. Dev. 6, 550 (2003).

${ }^{7}$ S. R. Byrn, R. R. Pfeiffer, G. Stephenson, D. J. W. Grant, and W. B. Gleason, Chem. Mater. 6, 1148 (1994)

${ }^{8}$ J. Schaefer, E. O. Stejskal, M. D. Sefeik, and R. A. McKay, Philos. Trans. R. Soc. London, Ser. A, 299, 593 (1981); R. G. Griffin, Nat. Struct Biol. 5, 508 (1998); F. Castellani, B. van Rossum, A. Diehl, M. Schubert, K. Rehbein, and H. Oschkinat, Nature (London) 420, 98 (2002); A. Petkova, Y. Ishii, J. J. Balbach, O. N. Antzutkin, R. D. Leapman, F. Delaglio, and R. Tycko, Proc. Natl. Acad. Sci. U.S.A. 99, 16742 (2002). ${ }^{9}$ C. P. Slichter, Principles of Magnetic Resonance, 3rd ed. (SpringerVerlag, Berlin, 1990); A. E. McDermott, Curr. Opin. Struct. Biol. 14, 554 (2004); M. Baldus, Angew. Chem., Int. Ed. 45, 1186 (2006); J. Schaefer, J. Magn. Reson. 137, 272 (1999); K. Schmidt-Rohr, W. Hu, and N. Zumbulyadis, Science 280, 714 (1998); J. D. van Beek, L. Beaulieu, H. Schafer, M. Demura, T. Asakura, and B. H. Meier, Nature (London) 405, 1077 (2000); C. M. Rienstra, L. Tucker-Kellogg, C. P. Jaroniec, M. Hohwy, B. Reif, M. T. McMahon, B. Tidor, T. Lozano-Perez, and R. G. Griffin, Proc. Natl. Acad. Sci. U.S.A. 99, 10260 (2002); D. Marulanda, M. L. Tasayco, A. McDermott, M. Cataldi, V. Arriaran, and T. Polenova, J. Am. Chem. Soc. 126, 16608 (2004); T. I. Igumenova, A. E. McDermott, K. W. Zilm, R. W. Martin, E. K. Paulson, and A. J. Wand, ibid. 126, 6720 (2004); S. Chimon and Y. Ishii, ibid. 127, 13472 (2005); A. T. Petkova, R. D. Leapman, Z. H. Guo, W. M. Yau, M. P. Mattson, and R. Tycko, Science 307, 262 (2005); A. Lange, K. Giller, S. Hornig, M. F. Martin-Eauclaire, O. Pongs, S. Becker, and M. Baldus, Nature (London) 440, 959 (2006); R. Mani, S. D. Cady, M. Tang, A. J. Waring, R. I. Lehrert, and M. Hong, Proc. Natl. Acad. Sci. U.S.A. 103, 16242 (2006); X. Chen, Z. H. Xu, X. Li, M. A. Shaibat, Y. Ishii, and R. S. Ruoff, Carbon 45, 416 (2007); S. Chimon, M. A. Shaibat, C. R. Jones, D. C. Calero, B. Aizezi, and Y. Ishii, Nat. Struct. Mol. Biol. 14, 1157 (2007).

${ }^{10} \mathrm{~K}$. Schmidt-Rohr and H. W. Spiess, Multidimensional Solid-State NMR and Polymers (Academic, London, 1994).

${ }^{11}$ Solid-State NMR Spectroscopy Principles and Applications, edited by M. J. Duer (Blackwell Science, Oxford, 2002); A. Medek, J. S. Harwood, and L. Frydman, J. Am. Chem. Soc. 117, 12779 (1995); A. McDermott, T. Polenova, A. Bockmann, K. W. Zilm, E. K. Paulsen, R. W. Martin, and G. T. Montelione, J. Biomol. NMR 16, 209 (2000).

${ }^{12}$ S. Aime, I. Bertini, and C. Luchinat, Coord. Chem. Rev. 150, 221 (1996).

${ }^{13}$ X. M. Zhang, C. Zhang, H. Q. Guo, W. L. Huang, T. Polenova, L. C. Francesconi, and D. L. Akins, J. Phys. Chem. B 109, 19156 (2005); Y. J. Lee, F. Wang, and C. P. Grey, J. Am. Chem. Soc. 120, 12601 (1998); W. Huang, L. C. Francesconi, and T. Polenova, Inorg. Chem. 46, 7861 (2007)

${ }^{14}$ K. Liu, D. Ryan, K. Nakanishi, and A. McDermott, J. Am. Chem. Soc. 117, 6897 (1995).

${ }^{15}$ T. Jovanovic and A. E. McDermott, J. Am. Chem. Soc. 127, 13816 (2005).

${ }^{16}$ A. R. Brough, C. P. Grey, and C. M. Dobson, J. Am. Chem. Soc. 115, 7318 (1993)

${ }^{17}$ A. Nayeem and J. P. Yesinowski, J. Chem. Phys. 89, 4600 (1988).

${ }^{18}$ H. Heise, F. H. Kohler, and X. L. Xie, J. Magn. Reson. 150, 198 (2001).

${ }^{19}$ Y. Ishii, N. P. Wickramasinghe, and S. Chimon, J. Am. Chem. Soc. 125, 3438 (2003).

${ }^{20}$ N. P. Wickramasinghe, M. Shaibat, and Y. Ishii, J. Am. Chem. Soc. 127, 5796 (2005).

${ }^{21}$ Y. Zhang, H. H. Sun, and E. Oldfield, J. Am. Chem. Soc. 127, 3652 (2005)

${ }^{22}$ G. Kervern, G. Pintacuda, Y. Zhang, E. Oldfield, C. Roukoss, E. Kuntz, E. Herdtweck, J. M. Basset, S. Cadars, A. Lesage, C. Coperet, and L. Emsley, J. Am. Chem. Soc. 128, 13545 (2006). 
${ }^{23}$ L. Ouyang, P. M. Aguiar, R. J. Batchelor, S. Kroeker, and D. B. Leznoff, Chem. Commun. (Cambridge) 2006, 744.

${ }^{24}$ Y. Ishii and N. P. Wickramasinghe, in Modern Magnetic Resonance, edited by G. A. Webb (Springer, Berlin, 2006), Vol. 1; G. Kervern, G. Pintacuda, and L. Emsey, Chem. Phys. Lett. 435, 157 (2007).

${ }^{25}$ N. P. Wickramasinghe and Y. Ishii, J. Magn. Reson. 181, 233 (2006).

${ }^{26}$ N. P. Wickramasinghe, M. A. Shaibat, and Y. Ishii, J. Phys. Chem. B 111, 9693 (2007).

${ }^{27}$ M. A. Shaibat, L. B. Casabianca, N. P. Wickramasinghe, S. Guggenheim, A. C. de Dios, and Y. Ishii, J. Am. Chem. Soc. 129, 10968 (2007).

${ }^{28}$ T. Oomomo, G. Maruta, and S. Takeda, Polyhedron 24, 2431 (2005).

${ }^{29}$ J. Grandjean, Clay Miner. 41, 567 (2006).

${ }^{30}$ A. Y. H. Lo, V. Sudarsan, S. Sivakumar, F. van Veggel, and R. W. Schurko, J. Am. Chem. Soc. 129, 4687 (2007).

${ }^{31}$ G. Mali, M. Sala, I. Arcon, V. Kaucic, and J. Kolar, J. Phys. Chem. B 110, 23060 (2006).

${ }^{32}$ G. Pintacuda, N. Giraud, R. Pierattelli, A. Bockmann, I. Bertini, and L. Emsley, Angew. Chem., Int. Ed. 46, 1079 (2007).

${ }^{33}$ P. S. Nadaud, J. J. Helmus, N. Hofer, and C. P. Jaroniec, J. Am. Chem. Soc. 129, 7502 (2007).

${ }^{34}$ S. Balayssac, I. Bertini, M. Lelli, C. Luchinat, and M. Maletta, J. Am. Chem. Soc. 129, 2218 (2007).

${ }^{35}$ N. P. Wickramasinghe, M. Kotecha, A. Samoson, J. Past, and Y. Ishii, J. Magn. Reson. 184, 350 (2007).

${ }^{36}$ R. Linser, V. Chevelkov, A. Diehl, and B. Reif, J. Magn. Reson. 189, 209 (2007).

${ }^{37}$ R. R. Ernst, G. Bodenhausen, and A. Wokaun, Principles of Nuclear Magnetic Resonance in One and Two Dimensions, 1st ed. (Oxford University Press, Oxford, 1987).

${ }^{38}$ A. Pines, M. G. Gibby, and J. S. Waugh, J. Chem. Phys. 59, 569 (1973).

${ }^{39}$ V. P. Chacko, S. Ganapathy, and R. G. Bryant, J. Am. Chem. Soc. 105, 5491 (1983)

${ }^{40}$ G. C. Campbell and J. F. Haw, Inorg. Chem. 27, 3706 (1988); M. Crozet, M. Chaussade, M. Bardet, L. Emsley, B. Lamotte, and J. M. Mouesca, J. Phys. Chem. A 104, 9990 (2000).

${ }^{41}$ E. De Vita and L. Frydman, J. Magn. Reson. 148, 327 (2001).

${ }^{42}$ G. N. La Mar, W. D. Horrocks, and R. H. Holm, NMR of Paramagnetic Molecules (Academic, New York, 1973).

${ }^{43}$ C. A. L. Filgueiras, A. Horn, R. A. Howie, J. M. S. Skakle, and J. L. Wardell, Acta Crystallogr., Sect. E: Struct. Rep. Online 57, m157 (2001).

${ }^{44}$ A. Abragam, Principles of Nuclear Magnetism (Oxford University, New York, 1961)

${ }^{45}$ G. Pintacuda, A. Kaikkonen, and G. Otting, J. Magn. Reson. 171, 233 (2004).

${ }^{46}$ K. Horiuchi, T. Asaji, and R. Ikeda, Phys. Rev. B 50, 6169 (1994).

${ }^{47}$ R. Calvo, P. R. Levstein, E. E. Castellano, S. M. Fabiane, O. E. Piro, and S. B. Oseroff, Inorg. Chem. 30, 216 (1991).
${ }^{48}$ B. R. Stults, R. S. Marianelli, and V. W. Day, Inorg. Chem. 18, 1853 (1979).

${ }^{49}$ J. Krzystek, G. J. Yeagle, J. H. Park, R. D. Britt, M. W. Meisel, L. C. Brunel, and J. Telser, Inorg. Chem. 42, 4610 (2003).

${ }^{50}$ H. Lee, T. Polenova, R. H. Beer, and A. E. McDermott, J. Am. Chem. Soc. 121, 6884 (1999).

${ }^{51}$ O. N. Antzutkin, Y. K. Lee, and M. H. Levitt, J. Magn. Reson. 135, 144 (1998).

${ }^{52}$ J. Herzfeld and A. E. Berger, J. Chem. Phys. 73, 6021 (1980).

${ }^{53}$ G. Facchin, M. H. Torre, E. Kremer, O. E. Piro, E. E. Castellano, and E. J. Baran, J. Inorg. Biochem. 89, 174 (2002).

${ }^{54}$ S. Datta and D. J. W. Grant, Nat. Rev. Drug Discovery 3, 42 (2004); P. M. Bummer, Crit. Rev. Ther. Drug Carrier Syst. 21, 1 (2004); R. B. Hammond, K. Pencheva, K. J. Roberts, and T. Auffret, J. Pharm. Sci. 96, 1967 (2007).

${ }^{55}$ P. J. Phillips, IEEE Trans. Electr. Insul. 13, 69 (1978); S. J. Wang, W. J. Oldham, R. A. Hudack, and G. C. Bazan, J. Am. Chem. Soc. 122, 5695 (2000); P. Chen, G. Z. Yang, T. X. Liu, T. C. Li, M. Wang, and W. Huang, Polym. Int. 55, 473 (2006); R. J. Curry, W. P. Gillin, J. Clarkson, and D. N. Batchelder, J. Appl. Phys. 92, 1902 (2002); R. B. Hammond, K. Pencheva, and K. J. Roberts, Faraday Discuss. 136, 91 (2007).

${ }^{56}$ K. G. Daniel, P. Gupta, R. H. Harbach, W. C. Guida, and Q. P. Dou, Biochem. Pharmacol. 67, 1139 (2004).

${ }^{57}$ R. C. Hoy and R. H. Morriss, Acta Crystallogr. 22, 476 (1967); G. Palenik, ibid. 17, 687 (1964).

${ }^{58}$ J. L. Battiste and G. Wagner, Biochemistry 39, 5355 (2000); J. Iwahara, D. E. Anderson, E. C. Murphy, and G. M. Clore, J. Am. Chem. Soc. 125, 6634 (2003); J. Iwahara and G. M. Clore, Nature (London) 440, 1227 (2006); B. Y. Liang, J. H. Bushweller, and L. K. Tamm, J. Am. Chem. Soc. 128, 4389 (2006); S. Cai, C. Seu, Z. Kovacs, A. D. Sherry, and Y. Chen, ibid. 128, 13474 (2006).

${ }^{59}$ J. J. Buffy, T. Hong, S. Yamaguchi, A. J. Waring, R. I. Lehrer, and M. Hong, Biophys. J. 85, 2363 (2003).

${ }^{60}$ M. Kotecha, N. P. Wickramasinghe, and Y. Ishii, Magn. Reson. Chem. 45, S221 (2007).

${ }^{61}$ J. C. Fanning and H. B. Jonassen, J. Inorg. Nucl. Chem. 25, 29 (1963).

${ }^{62}$ R. W. Martin and K. W. Zilm, J. Magn. Reson. 165, 162 (2003).

${ }^{63}$ F. Delaglio, S. Grzesiek, G. W. Vuister, G. Zhu, J. Pfeifer, and A. Bax, J. Biomol. NMR 6, 277 (1995).

${ }^{64}$ G. Metz, X. L. Wu, and S. O. Smith, J. Magn. Reson., Ser. A 110, 219 (1994).

${ }^{65}$ S. Hediger, B. H. Meier, and R. R. Ernst, Chem. Phys. Lett. 240, 449 (1995); A. C. Kolbert and A. Bielecki, J. Magn. Reson., Ser. A 116, 29 (1995).

${ }^{66}$ B. Bleaney, J. Magn. Reson. (1969-1992) 8, 91 (1972).

${ }^{67}$ A. Bielecki and D. P. Burum, J. Magn. Reson., Ser. A 116, 215 (1995), 